\title{
Review
}

\section{Co- and Post-Translational Protein Folding in the ER}

\author{
Lars Ellgaard $^{1 *}$, Nicholas McCaul ${ }^{2 \dagger}$, Anna Chatsisvili ${ }^{2 \dagger}$ and Ineke Braakman ${ }^{2 *}$ \\ ${ }^{1}$ Department of Biology, University of Copenhagen, Copenhagen, Denmark \\ ${ }^{2}$ Cellular Protein Chemistry, Faculty of Science, Utrecht University, Utrecht, The Netherlands \\ *Corresponding authors: Lars Ellgaard, lellgaard@bio.ku.dk and Ineke Braakman, i.braakman@uu.nl
}

\begin{abstract}
The biophysical rules that govern folding of small, single-domain proteins in dilute solutions are now quite well understood. The mechanisms underlying co-translational folding of multidomain and membrane-spanning proteins in complex cellular environments are often less clear. The endoplasmic reticulum (ER) produces a plethora of membrane and secretory proteins, which must fold and assemble correctly before ER exit - if these processes fail, misfolded species accumulate in the ER or are degraded. The ER differs from other cellular organelles in terms of the physicochemical environment and the variety of ER-specific protein modifications. Here, we review chaperone-assisted co- and post-translational folding and assembly in the ER and underline
\end{abstract}

the influence of protein modifications on these processes. We emphasize how method development has helped advance the field by allowing researchers to monitor the progression of folding as it occurs inside living cells, while at the same time probing the intricate relationship between protein modifications during folding.

Keywords chaperones, disulfide-bond formation, endoplasmic reticulum, folding enzymes, N-glycosylation, protein folding

Received 24 December 2015, revised and accepted for publication 3 March 2016, uncorrected manuscript published online 7 March 2016, published online 22 April 2016
By nature, co-translational folding as it occurs while the protein is being synthesized on the ribosome differs significantly from post-translational folding investigated in the test tube. For instance, a higher rate of translation can influence folding either positively or negatively depending on the nature of the protein (1), and translational attenuation (ribosome stalling) at specific positions within the mRNA sequence has been found to increase the folding efficiency of multidomain proteins (2). Protein folding can initiate inside the ribosomal exit tunnel, e.g. through helix formation in the lower tunnel (3-6). Moreover, a small $\mathrm{Zn}^{2+}$-binding domain containing 29 residues can be fully folded within the protective environment of the

\footnotetext{
†These authors contributed equally to this work.
}

ribosomal exit tunnel (7). Crosstalk between this tunnel and the nascent chain has been shown to induce structural rearrangements both inside the exit tunnel and at the site of chain elongation, the peptidyltransferase center $(8,9)$. These structural rearrangements can fine-tune the environment inside the ribosome to accommodate the divergent chemistries of different amino acid side chains, resulting in an adaptable environment to allow co-translational folding. In addition, this crosstalk can modulate elongation rate $(10,11)$, recruitment of targeting factors [e.g. signal-recognition particle (SRP)] and translocase activity $(12-15)$.

Co-translational translocation across the endoplasmic reticulum (ER) membrane usually requires the presence of 
an N-terminal signal sequence. Upon emergence from the ribosomal exit tunnel, the signal sequence is recognized by SRP in the cytosol (Figure 1). An important property of SRP is that it halts further translation to keep the nascent polypeptide in a translocation-competent state (16). Only after binding the SRP receptor at the ER membrane and docking of the ribosome-nascent chain (RNC) complex on the Sec61 translocon, the protein complex that constitutes the channel through which the protein is translocated across or inserted into the membrane, is translation reinitiated. The textbook knowledge described above has recently been expanded at multiple levels. Peroxisomal membrane proteins employ ER translocons to get inserted into the membrane (17) but do not have discernible ER-targeting signal peptides, and proteins without signal peptides still reach the ER in Caenorhabditis elegans, provided the SRP-competitor nascent polypeptide-associated complex is absent (18).

Recent electron microscopy (EM) structures of the RNC-SRP and RNC-translocon complexes $(19,20)$ match the biochemical/biophysical evidence (3-6) that transmembrane domains can adopt a helical structure early in the ribosome and maintain it in the translocon and upon insertion into the ER membrane. Studies by Helenius and coworkers on co-translational folding of ER-targeted proteins attached to the ribosome by C-terminal extensions provide evidence that the ribosome-translocon complex and associated proteins offer a protective environment to allow early co-translational folding of the nascent chain and that the translocon can accommodate alpha-helical conformations, but not complete folding into the tertiary structure $(21,22)$.

While the principles of co-translational folding described above have been derived in part from in vitro studies with purified components, they still apply in vivo. As recently pointed out (23), post-translational folding predominates over co-translational folding in the cell: the average half-time for folding of proteins is 30-60 min, while the translation rate in mammalian cells is approximately three to five amino acids per second and hence it takes only $\sim 2 \mathrm{~min}$ to synthesize an $\sim 50$-kDa protein (24). Not only that, but $\sim 50 \%$ of available structures for single-domain proteins show $\mathrm{N}$ - and C-termini in close proximity, a feature that is present in many multidomain proteins as well (Figure 2). For such proteins, folding cannot progress to completion until translation is finished and the C-terminus has exited the ribosomal tunnel.

\section{Making an Entry - The Role of Signal Peptide Cleavage}

Once the RNC complex has been handed off to the translocon, the signal sequence is inserted into the membrane and translation continues. Signal sequences can be weak, leading to multiple locations of a protein, for instance both ER and cytosol $(30,31)$. N-terminal modifications, such as $\mathrm{N}$-myristoylation (see below), can also lead to dual targeting of proteins (for example to the ER and mitochondria) $(32,33)$. Once docked to the ER, in most type II transmembrane proteins the signal sequence stably integrates into the lipid bilayer, forming a signal anchor, whereas nearly all secreted and many type I transmembrane proteins contain a cleavable signal peptide. Insertion of the signal sequence into the membrane is an important determinant of their topology. Signal peptide-containing proteins largely follow the 'positive-inside rule' (34) of keeping positively charged amino acids (lysine and arginine) flanking the hydrophobic stretch on the cytosolic side of the membrane. Hydrophobicity determines whether a polypeptide stretch will become a transmembrane anchor, and flanking charges determine topology. Recently, the Skach laboratory showed that for at least some signal anchors (and perhaps including many signal peptides, as they function as signal anchors until cleaved) these rules are fulfilled in sequence: the $\mathrm{N}$-terminal signal peptide is inserted head first toward the ER lumen, and then an inversion in the ribosome-translocon complex is needed to acquire native topology with the N-terminus in the cytosol (13). This contrasts with current textbook knowledge that reports loop-wise insertion of signal peptides, with the N-terminus in the cytosol from the start (35). Both are bound to occur, and a single protein can end up with different topologies (30). For signal-anchor and multispanning transmembrane proteins, the eventual topology is (or multiple topologies are) determined by multiple factors including charge, hydrophobicity, lipid composition and folding of the $\mathrm{N}$-terminal region, a topic that is beyond the scope of this review. 


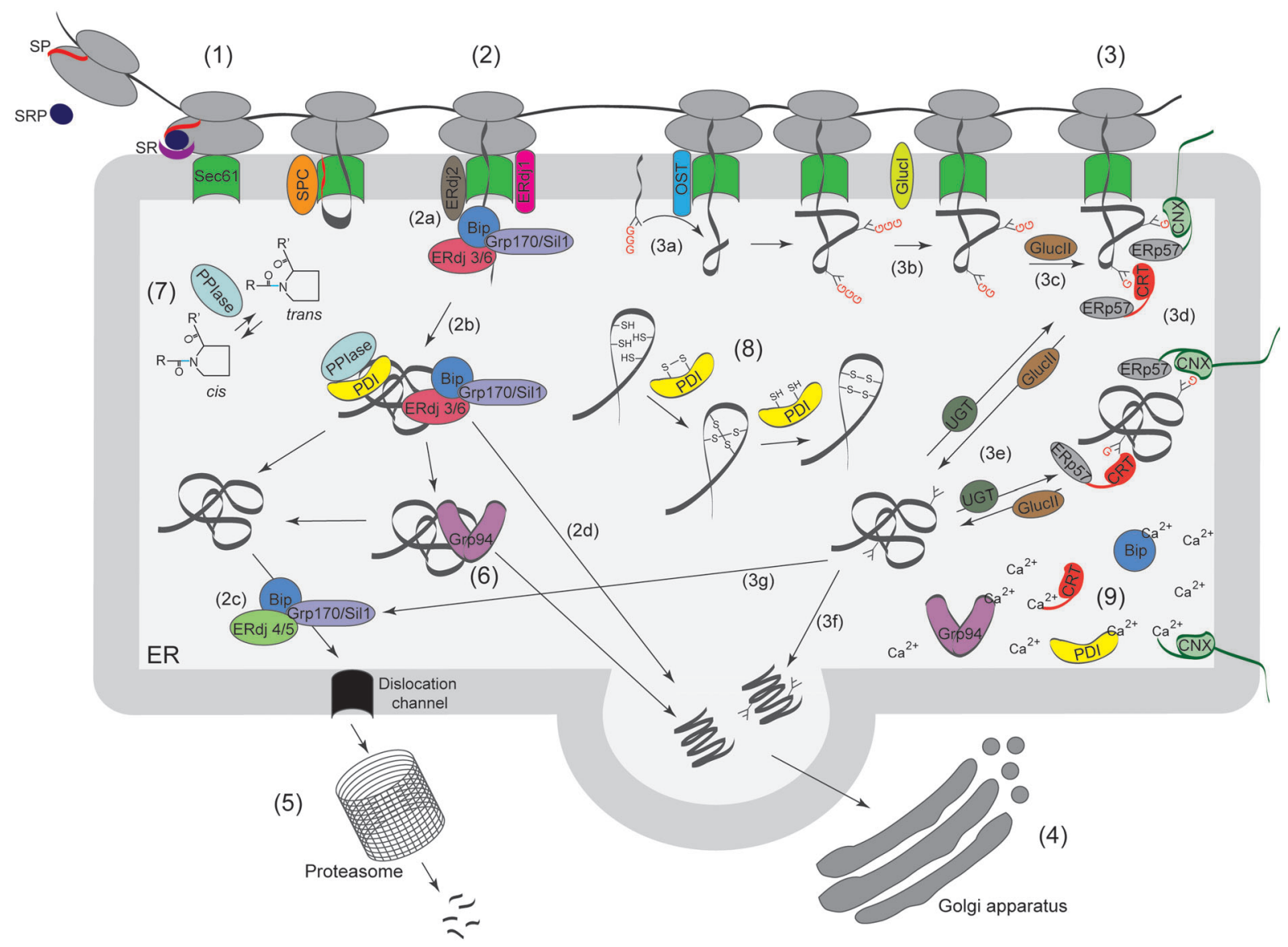

Figure 1: Protein folding in the ER. Newly synthesized proteins destined for the secretory pathway are targeted to the ER membrane by a signal peptide (SP), which gets cleaved by the signal - peptidase complex (SPC) (1). Signal sequences that are not cleaved serve to anchor proteins in the membrane. Once the polypeptide emerges from the Sec61 translocon, folding is assisted by chaperones and folding enzymes. Two of the main chaperone systems are BiP (2) and calnexin (CNX)/calreticulin (CRT) (3). BiP acts in concert with its co-chaperones of the ERdj family and the nucleotide-exchange factors Sil1 and Grp170, which also acts as chaperone in its own right. For recruitment to translating ribosomes and for protein translocation, BiP functions together with ERdj1 and ERdj2, respectively (2a). In protein folding, BiP cooperates with ERdj3 and ERdj6 (2b), whereas in ER-associated degradation of misfolded proteins, it collaborates with ERdj4 and ERdj5 (2c). Upon correct folding (2d), proteins exit the ER and travel to the Golgi (4), whereas misfolded proteins are dislocated to the cytosol for proteasomal degradation (5). The lectin chaperones CNX/CRT assist glycoprotein folding. $\mathrm{N}$-glycosylation is initiated by the oligosaccharyltransferase (OST) complex, which transfers the $\mathrm{Gl}_{3} \mathrm{Man}_{9} \mathrm{GlcNAc}_{2}$ core oligosaccharide from a dolichol precursor to Asn residues of Asn-X-Ser/Thr motifs present on nascent polypeptides (3a). Glucosidases I (Glucl) and II (Glucll) then trim the two outer glucoses $(G)$ in sequence $(3 b, 3 c)$ and the resulting mono-glucosylated polypeptides are recognized by CNX/CRT. Their associating co-chaperone ERp57 facilitates disulfide-bond formation in the glycosylated substrate (3d). Glycoproteins exit the CNX/CRT cycle after trimming of the last glucose residue by Glucll (3e). Correctly folded glycoproteins exit the ER (3f) and travel to the Golgi (4), whereas incompletely folded glycoproteins re-enter the CNX/CRT cycle after the readdition of one glucose residue by UDP-glucose glycoprotein glucosyltransferase (UGT) (3e). Terminally misfolded glycoproteins are directed via, e.g. BiP to a dislocation channel (3g) and the cytosol for degradation by the proteasome (5). Other important folding factors include Grp94 (6), which assists folding of proteins handed over by BiP, peptidyl-prolyl isomerases (PPlases) (7), which catalyze cis-trans isomerization of X-Pro peptide bonds, and protein disulfide isomerases (PDIs) (8), which catalyze the formation, reduction and isomerization of disulfide bonds. Several folding factors bind $\mathrm{Ca}^{2+}(9)$, which is important for ER homeostasis and protein folding. $\mathrm{R}, \mathrm{R}^{\prime}$ : polypeptide chains. 


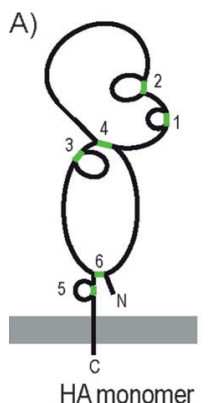

HA monomer

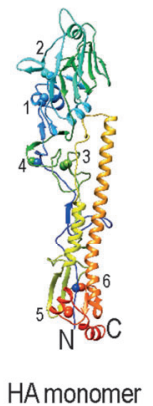

HA monomer

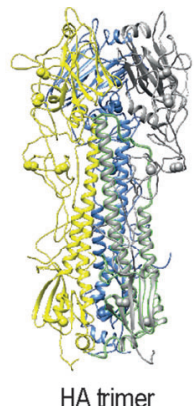

HA trimer
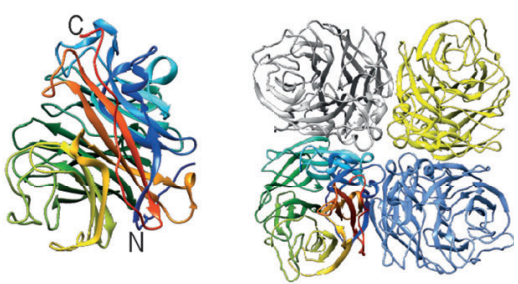

NA monomer
NA tetramer

B)

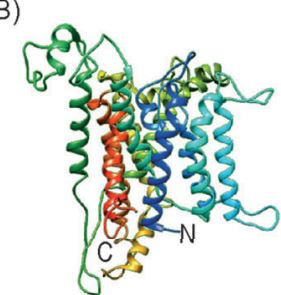

$\operatorname{Sec} 61 a$

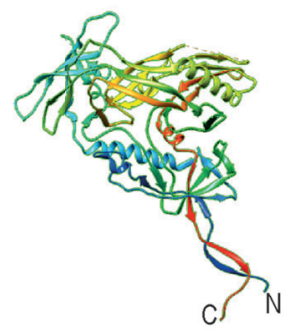

HIV-1 gp120

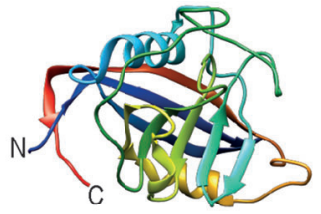

CypB

Figure 2: Protein structures with N-C proximity. A) From left: 'Bird' representation of influenza virus hemagglutinin (HA) drawn by Prof. Ari Helenius as in Table of Contents. Numbers indicate disulfide bonds in order of formation during folding. Crystal structures of HA ectodomain monomer (PDB: 1HA0; 25) showing $\mathrm{N}$ - and C-terminal contacts. HA ectodomain trimer (PDB: 1HGD; 26) with each subunit represented by a different color. NA ectodomain monomer (PDB: 4QN3; 27) and NA ectodomain tetramer (PDB: 4QN3) with each subunit represented by a different color. B) From left: Cryo-EM structure of Sec61 $\alpha$ (PDB: 4CG6; 19), crystal structures of HIV-1 gp120 (PDB: 4TVP; 28) and cyclophilin B (CypB, PDB 3ICH; 29), which all show proximity of $\mathrm{N}$ - and C-termini in the folded state. HA monomer, Sec61 $\alpha$, gp120 and CypB structures are rainbow colored, with a blue $\mathrm{N}$-terminus and a red $\mathrm{C}$-terminus.

Early studies $(36,37)$ have established that signal peptides are cleaved by the signal-peptidase complex during translation, as soon as they emerge from the translocon; the cleavage site obeys some rules concerning residues -1 and -3 (small hydrophobic), but knowledge is insufficient to predict cleavage accurately (38). This would suggest that the residues downstream of the cleavage site play no role for cleavage efficiency. However, a proline next to the cleavage site does inhibit cleavage $(39,40)$ and residues further downstream can influence signal-peptide cleavage; for example, HIV-1 Env (41), HCMV US11 (42) and EDEM1 (43) lose their signal peptides post-translationally, effectively acting as type II signal anchors for the early period of the protein's life. Cleavage of HIV-1 Env required some folding (44), suggesting interplay between the signal peptide and the folding molecule, while delayed cleavage of EDEM1 affects its substrate specificity. These signal sequences tend to be longer than the usual 15-25 residues and likely form stable transmembrane domains (45), as does the signal sequence of Arenaviral glycoprotein C precursors (45). Although not a direct study on the role of signal-sequence cleavage on folding, the Helenius laboratory showed that a signal anchor as opposed to a cleavable signal peptide allowed complete domain folding at a shorter nascent chain length (22), suggesting that tethering of a protein's $\mathrm{N}$-terminus to the ER membrane can be productive for folding.

Signal-peptide mutations have been associated with a variety of diseases including Ehlers-Danlos syndrome (46), autosomal dominant familial isolated hypoparathyroidism (47), familial central diabetes insipidus (48), factor X deficiency (49), idiopathic pulmonary fibrosis (50), familial expansive osteolysis (51) and breast cancer (52). While mutations often block SRP binding, translocation or cleavage $(48,49,53)$, mutations in preprocollagen $\mathrm{V}(\alpha 1)(46)$ and IL-10 (50) signal peptides were shown to be more subtle with an equally severe outcome: they block secretion 
of mutant protein despite an unchanged electrophoretic mobility, which suggests similar (but likely not identical) signal-peptide cleavage. The identity of the signal sequence clearly influences a protein's cleavage as well as its N-glycosylation (54,55), implying effects on folding. Indeed, both timing and position of signal-peptide cleavage affect folding and hence function of proteins. An alternative cause for disease-related signal peptide (cleavage) defects may lie in the non-targeting functions of signal peptides (56).

Taken together, these data suggest that in many cases signal sequences are more than simply cellular postcodes and in fact have diverse post-targeting roles in folding, maturation and function.

\section{Folding and Assembly of Multidomain and Membrane-Spanning Proteins}

Proteins do not function alone. Their interactions range from short transient ones within functional networks to long-lived in the stable oligomers formed during biosynthesis. Many proteins in the secretory pathway are oligomeric and their assembly has been reported to occur during late folding steps or after folding, especially for homo-oligomeric proteins. Although some cytosolic proteins were found to assemble while still on the polysome (57-60), homo-oligomerization in the ER seems mostly post-translational (57). This appears counterintuitive, as the polysome limits spacing between growing nascent chains and would allow early interactions. Oligomerization has been well studied for viral glycoproteins, such as influenza virus hemagglutinin (HA) $(57,61)$ and vesicular stomatitis virus (VSV) G protein $(62,63)$, which both homotrimerize after or toward the end of subunit folding; HA then forms a stable, irreversible trimer (57), whereas the VSV G trimer remains in equilibrium with its (folded) monomers (64).

The vast majority of oligomeric proteins consist of different subunits for which co-translational assembly has been reported. A well-studied example is the antibody molecule (immunoglobulin, Ig), whose protomer is a heterotetramer of two light chains (L) and two heavy chains (H). IgG was the first protein for which heteromeric assembly was examined (65,66): in 1979, Bergman and Kuehl demonstrated that $\mathrm{L}$ assembles after completion of translation and translocation, but assembles onto $\mathrm{H}$ chains during their synthesis, leading to a detectable $\mathrm{H}-\mathrm{L}$ assembly intermediate. For another IgG subtype the H homodimer is the dominant assembly intermediate, consistent with a co-translational assembly of $\mathrm{H}$ onto another $\mathrm{H}$ chain, most likely of 2 nascent $\mathrm{H}$ chains on the polysome $(65,66)$. The assembling $\mathrm{L}$ chain was shown to be complete, released from the ribosome and contain at least one folded domain, but more recent work by the Hendershot laboratory has demonstrated that the assembly involves templated folding. Here, the major Hsp70 chaperone in the ER, $\mathrm{BiP}$, is displaced from the unfolded $\mathrm{H}$ and $\mathrm{L}$ domains by their assembly partner (67-70). A domain that requires template-assisted folding always teams up with a folded domain that is fit to act as template.

This same theme of template-assisted folding is likely to be general, as the T-cell receptor (TCR) follows the same principle in assembly of the Ig-like domains in its alpha and beta chains (71). In this case, templating not only supports folding but could also be functional, as it may increase specificity within the T-cell repertoire (71). The generality does not stop at Ig domains as (again) the TCR alpha chain needs other TCR subunits to retain the weak transmembrane domain of the alpha chain in the ER membrane (72). In the absence of a partner subunit to assemble with, the alpha chain slips into the ER lumen, where the hydrophobic region is recognized by $\mathrm{BiP}$, resulting in rapid degradation of the TCR alpha chain by the proteasome in the cytosol. For details on ER-associated degradation (ERAD), we refer to the review by Molinari and coworkers in this issue (73).

Proteasomal degradation of unassembled oligomer subunits is a common theme in the assembly of hetero-oligomers and especially for complex proteins consisting of more than two (up to even eight) different subunits. Examples are the TCR and acetylcholine receptor, but also several protein complexes required for protein biosynthesis in the ER, including the Sec61 translocon and the oligosaccharyltransferase (OST) (see below and 74-76). Formation of complex quaternary structure in the ER has been characterized well for only a dozen proteins, for some already more than 20 years ago. An insightful review on this that has withstood the test of time was published in 1989 by Hurtley and Helenius (77). In most 
studied cases, the expression of a single subunit is regulated and determines the amount of oligomer formed, while the others are made in excess with orphan subunits being degraded. Regulation by more than a single subunit does occur, particularly in heterogeneous assemblies such as the TCR (72).

The atomic interactions involved in protein folding (hydrogen bonding, electrostatic and Van der Waals interactions) are identical to those involved in protein assembly/oligomerization, in transient interactions and, of course, then also identical to those involved in the assembly of domains within a multidomain protein. Most eukaryotic proteins are large and consist of more than a single domain, such as immunoglobulins, which possess several domains that fold relatively independent of each other and usually are organized as beads on a string. However, as is true for single-domain proteins (78), large proteins often have proximal $\mathrm{N}$ - and C-termini as well (Figure 2), which precludes vectorial folding and involves interactions of parts of the molecule that are distant in the linear amino acid sequence. Some domains may consist of a contiguous polypeptide chain, whereas other domains must integrate distant sequences. The low-density lipoprotein receptor (LDLR), despite its strictly linear domain organization, forms distant interactions during the on-pathway folding process (79). Non-native interdomain interactions during folding may well be the rule for most proteins. The structure of these proteins, such as influenza virus HA (Figure 2), with proximal ectodomain $\mathrm{N}$ - and C-termini and with trimerization involving the transmembrane and/or membrane-proximal domains, may well be the explanation for the counterintuitive post-translational homo-oligomerization. Even though the trimer subunits appear in close proximity as nascent chains in the ER, only after advanced folding the interaction surfaces for trimerization will have formed (Figure 2), which precludes their co-translational trimerization.

A special type of multidomain proteins are the multimembrane-spanning proteins, which during folding have domains or at least some amino acid residues in the cytosol, the ER lumen as well as in the ER membrane. These three topologies offer advantages, as compartmental separation provides a phase separation within the polypeptide sequence and prevents separated polypeptide parts from aggregating with each other. The challenge is the coordinated folding of all three protein domains, perhaps requiring concerted actions of chaperones in all three topological domains. The folding of complex multimembrane-spanning proteins, such as $A B C$ transporters and G protein-coupled receptors (GPCRs), has barely been studied, but some intricate translocation and folding studies have been published and the many high-resolution structures do suggest common themes. Co-translationally, transmembrane segments are inserted into the ER membrane loop by loop, with downstream sequences 'pushing' N-terminal segments out of the Sec61 translocon into the lipid bilayer (15,80-82).

The Skach laboratory showed that Aquaporin1 (AQP1) is inserted co-translationally in the native topology, whereas Aquaporin4 (AQP4) needs to rearrange and even invert some of its transmembrane segments after translocation to acquire its functional conformation $(83,84)$.

\section{The First Encounter - Molecular Chaperones}

Once the N-terminus of a polypeptide emerges from the Sec61 channel, it starts to fold. In this process, it needs the assistance of several folding factors: the molecular chaperones and folding enzymes (Figure 1).

Molecular chaperones are defined as 'proteins that interact with, stabilize or help a non-native protein to acquire its native conformation, but are not present in the final functional structure' (85). They reside in the nucleus, cytosol, $\mathrm{ER}$, mitochondria and in plants also in chloroplasts. The major ER-resident chaperones are the Hsp70 BiP (Grp78) (86), the Hsp90 Grp94 (gp96) (87) and the lectin chaperones calnexin (CNX) and calreticulin (CRT) (88), which are unique to the ER and will be discussed with $\mathrm{N}$-linked glycosylation below.

$\mathrm{BiP}$ is the most abundant and most versatile of ER chaperones. It contributes to protein folding (89), is always present in misfolded protein aggregates and retains misfolded and unfolded proteins in the ER (90-93), assists retrograde transport of proteins destined for proteasomal degradation (94) and regulates the unfolded protein response (95). BiP helps maintain $\mathrm{Ca}^{2+}$ homeostasis $(70,96)$, which indirectly is crucial for protein folding as most ER-resident 
folding factors bind abundant $\mathrm{Ca}^{2+}$ and depend on it for function (Figure 1). Calcium levels directly affect folding of $\mathrm{Ca}^{2+}$-binding proteins, such as integrins $(97,98)$ and LDL-A and EGF repeat-containing proteins including the LDLR and LRP $(99,100)$. Fitting with BiP's role as master regulator of ER function (86), its deletion does not generate viable cells or mice: BiP-knockout mice show peri-implantation lethality (101). Inducible inactivation by subtilase cytotoxin (102) or BiP depletion has confirmed the importance of $\mathrm{BiP}(103)$.

Client binding by BiP is regulated by its ATPase cycle through the actions of J proteins (ERdj1-7) (104) and nucleotide-exchange factors (Grp170, Bap/Sil1) $(105,106)$ (Figure 1). $\mathrm{BiP}$ is the chaperone that an emerging nascent chain is likely to encounter first, before any other chaperone, because one of the J proteins that recruit $\mathrm{BiP}$ and activate its ATPase activity, ERdj2/Sec63, is a component of the translocon. CNX competes for binding of glycoproteins (see below), but even then BiP may facilitate translocation $(107,108)$.

While BiP binds perhaps even all proteins that pass through the ER, its best-characterized role is in folding and assembling antibody molecules. Haas and Wabl identified BiP as Ig-binding chaperone (109), and the Hendershot laboratory showed that BiP holds disordered Ig domains in antibody $\mathrm{H}$ and $\mathrm{L}$ chains as well as in the TCR until handing over to the assembly partner $(68,70,72)$. Assembly with the stable partner-Ig domain induces folding of the disordered domain into a stable native oligomer, which involves a trapped folding intermediate that requires the proline-isomerase CypB to progress to the functional fold (110). Studies like this that clarify the molecular effect of a chaperone on a folding protein in the ER still are rare, even though most ER-resident folding factors have been shown to be essential for a plethora of processes and phenotypes.

The ERdJs, as co-chaperones for BiP, recruit BiP to specific processes, such as translocation $(111,112)$, folding (113-115) and degradation (116-118), and may bind clients first and independent of $\mathrm{BiP}$ before presenting them to the chaperone. Although reported crucial for folding, there is no evidence (yet) that any of the J proteins affect protein folding directly and independently of BiP (Figure 1). Moreover, there is no evidence (yet) that $\mathrm{BiP}$ itself directly affects folding of a protein, meaning that it would direct folding and change substrate conformation. Like other Hsp70s it is thought to be a rather passive chaperone that holds and thereby on the one hand prevents misfolding and aggregation and on the other hand maintains folding competence in the client protein $(71,86,119)$.

The other major ER-resident chaperone of a general family is the Hsp90 Grp94, which caters to a more limited clientele $(120,121)$, including Toll-like receptors (TLRs), integrins (122-125), immunoglobulins (126,127), collagen (128), insulin-like growth factors $(129,130)$ and members of the LDLR family $(121,123)$. Although ATP binding and hydrolysis are essential steps for Grp94 chaperone activity (131), the exact mechanism of action of Grp94 has not been elucidated. Recently, only a single putative co-chaperone family of Grp94 has been identified, the Canopy (CNPY) family (132), including the TLR-specific CNPY3/PRAT4A (133) and CNPY5 (Mzb1/pERp1) (133-136).

Hsp90s usually bind substrates after Hsp70s and indeed, $\mathrm{BiP}$ hands over newly synthesized immunoglobulin to Grp94 (137) (Figure 1). How Grp94 affects folding is not clear, but it was shown to be essential in many processes in the ER, including protein folding (121), ER quality control and stress response (138) as well as $\mathrm{Ca}^{2+}$ buffering (139).

Next to the abundant general and ER-specific molecular chaperones, the ER contains various classes of so-called folding enzymes, which catalyze co- and post-translational modifications important for protein folding. A special class of folding enzymes are the peptidyl-prolyl cis-trans isomerases (PPIases), which catalyze the isomerization of the peptide bond preceding proline residues (prolyl bonds) from trans to cis orientation and back (Figure 1). The rotation of the prolyl bond has a very high activation energy (140) resulting in extremely slow isomerization reactions with time constants of $10-100$ seconds at $25^{\circ} \mathrm{C}$. As such, proline isomerization often is a major rate-limiting step during protein folding, unfolding and refolding (141 - 147). This is obvious considering that almost every protein contains proline residues (148). Prolines are added by the ribosome in trans $(149,150)$ and multiple cis-trans isomerizations may be needed during folding $(29,143,151,152)$. In protein structures $5-7 \%$ of prolyl bonds are in cis (153-155), with structural analyses showing almost half 
(43\%) of PDB structures containing at least one cis prolyl bond. In vitro refolding studies on disulfide-containing proteins, such as ribonuclease (142), conotoxins (156) and minicollagen-1 (157), have revealed that slow proline isomerization can be rate limiting for oxidation and reduction of disulfide bonds, which can be accelerated by PPIases. PPIases clearly are important and general components of the folding machinery that may well cover all folding proteins as their substrates.

It is therefore surprising that different classes of PPIases exist: the cyclophilins (Cyps) (158), which are inhibited by cyclosporin A, the FKBPs, which are inhibited by FK506, and the parvulins, which are found to work on folded proteins $(159-161)$. Functional studies in vitro have shown that prolyl bonds can be isomerized by either Cyp or FKBP family enzymes with kinetics shown to be dependent upon neighboring residues (162-164). CypB-dependent isomerization of a single proline residue controls disulfide-linked assembly and secretion of IgG (165, see above), and CypB directly catalyzes triple-helix formation of type III collagen (143, see below).

To what extent PPIases exhibit substrate specificity in vivo has yet to be tested extensively. Such specificity may be provided by the networking with other ER-resident folding factors, as multiple PPIase-containing protein complexes have been found that include BiP, Grp94, oxidoreductases, CRT and CNX (152). In fact, the entire ER folding machinery consists of networks of chaperones and folding enzymes, which act on substrates together, either simultaneously or in sequence $(152,166,167)$ (Figure 1).

\section{The Role of Protein Modifications}

Protein modifications, often occurring co-translationally, play an integral and crucial function in ER protein folding. This is especially the case for the addition of disulfide bonds and N-glycans, but other modifications specific to the ER also affect the folding process. Importantly, the development of methods to monitor the introduction of such modifications co-translationally in living cells has been critical. Several such methods were pioneered in the Helenius laboratory (see Box 1), and have enabled us to understand at a quite detailed level how proteins fold inside the ER of living cells.

\section{Box 1. Techniques for Studying Co-Translational Folding in the ER}

Recent years have seen the application of sophisticated biophysical techniques, such as NMR spectroscopy $(168,169)$, mass spectrometry (170) and electron microscopy $(3,7)$ to study co-translational folding. While electron microscopy has been instrumental in generating structural insights into the complex between ribosome, nascent chain and translocon $(19,20,171)$, given the complex environment of the ER lumen, such techniques are not likely to become applicable to ER protein folding in the near future. Here, we provide an overview of the most commonly used methods to study co-translational protein folding in the ER.

Pulse-chase approaches to study protein folding as pioneered by Helenius and coworkers involve metabolic radiolabeling of newly synthesizing proteins $(24,61,172)$, which allows folding to be studied with time. By combining radiolabeling with immunoprecipitation and both non-reducing and reducing SDS-PAGE, oxidative folding can be visualized as electrophoretic mobility changes caused by changes in the compactness of the SDS-denatured protein due to disulfide bonding. As an alternative, radiolabeled amino acids can be incorporated by in vitro translations, whereby only the mRNA of the protein of interest is translated. Ribosomes and translation components are supplied by a cellular extract, normally rabbit reticulocyte or wheat germ lysate, and these systems are supplemented with ER-derived membranes (semi-permeabilized cells; 173, 174) or ER-derived microsomes $(175-177)$ to study co-translocational processes of membrane and secretory proteins.

By using short pulse times in relation to a protein's synthesis time and compounds (e.g. cycloheximide) that inhibit chain elongation, folding differences can be probed even of nascent chains still attached to the ribosome. Analysis of nascent chains has been taken to the next level by the use of 'diagonal' 2D electrophoresis where the first dimension is non-reducing and the second dimension is reducing SDS-PAGE. 
By comparing positions of bands relative to the diagonal, intrachain as well as interchain disulfide bonds are distinguished, and it is possible to estimate how extended a nascent chain must become before it attains disulfides or interacts with chaperones and oxidoreductases (178). Co-translational folding can also be studied on ribosome-arrested chains of different lengths. Removal of the stop codon from mRNA translated in vitro prevents termination of the polypeptide chain. Folding of the ribosome-arrested chain can then be followed, for instance to determine the minimum distance from the ribosomal peptidyltransferase center needed for domain folding, glycosylation and disulfide-bond formation $(22,55)$. In the case of proteins without disulfide bonds, which will not display a mobility shift on SDS-PAGE gels when comparing reducing and non-reducing conditions, limited proteolysis is a tried and proven approach. It works on the principle that folded domains are less accessible to proteases than proteins in a more extended conformation. Limited proteolysis therefore will provide global information on protein stability as well as detailed information on protein folding and assembly $(179,180)$.

An elegant additional method to study protein folding is the use of conformation-specific antibodies. During the folding process epitopes will form or become shielded rendering them inaccessible. Using antibodies specific for different folded states in combination with broadly recognizing antibodies allows visualization of folding intermediates by SDS-PAGE (24). Antibodies directed against specific domains/regions/peptides are useful in particular when used in conjunction with limited proteolysis to identify protease-resistant domains.

As $\mathrm{N}$-linked glycosylation plays such a large role in protein folding in the ER, it is also often examined to provide information about the folding state of proteins. When N-glycans become modified in the Golgi, they become resistant to digestion by endoglycosidase $\mathrm{H}$ (endo $\mathrm{H}$ ), but remain sensitive to $\mathrm{N}$-glycanase $\mathrm{F}$ (PNGase F). This difference is used to identify the cellular localization of proteins during biosynthesis (181). Specific manipulation of cellular exoglycosidases, such as $\alpha$-mannosidases or glucosidases combined with the above approaches, identifies the roles of specific glycan structures. The Helenius laboratory used these approaches to delineate the glycan regulation of the calnexin cycle $(76,94,182)$.

\section{Disulfide-Bond Formation}

Disulfide bonds are introduced into most proteins synthesized in the ER and primarily function to indirectly stabilize the native protein structure and oligomeric complexes. They play important functions during folding $(183,184)$, and missense mutations that replace a cysteine in a disulfide (or introduce an additional cysteine into the protein) frequently are detrimental for function, proper folding or protein stability. As a consequence, such mutations often are disease causing, as in the case of insulin where cysteine mutations can lead to diabetes (185).

Treatment of cells with dithiothreitol (DTT), a cellpermeable reducing agent, has been particularly useful in investigating the importance of disulfide-bond formation for protein folding in live cells, as pioneered in the Helenius laboratory (186-188). Such studies have made it clear that disulfide-bond formation often is essential for folding and that for many proteins it occurs already co-translationally. Various fully synthesized proteins that have been kept reduced, however, can also fold to the native conformation upon removal of DTT $(186,189)$. Influenza virus HA has even been established to fold to completion under in vitro conditions upon formation of a few specific disulfide bonds in the intact ER (190). This fits well with the finding that even conserved disulfides can be dispensable for folding and function, while others are essential (191).

Disulfide-bond formation starts co-translationally, with post-translational reshuffling (isomerization) occurring in what is often the rate-limiting step in folding $(192,193)$. While certain proteins, such as influenza HA, go through defined folding steps characterized by folding intermediates containing native long-range disulfide bonds $(24,178)$, slow-folding proteins such as HIV-1 envelope glycoproteins initially form disulfide bonds that then need to undergo extensive isomerization before the native conformation is reached (44). In the case of the LDLR, long-range 
non-native disulfide bonds even form abundantly during on-pathway folding to the native state (79). For this multidomain protein, folding therefore does not proceed in a vectorial domain-by-domain order, but rather through isomerization of commonly occurring intradomain non-native disulfides. As discussed above, many proteins have proximal $\mathrm{N}$ - and C-termini, which may suggest that peripheral contacts are favorable for efficient folding, perhaps by shielding hydrophobic sites, reminiscent of the hydrophobic collapse observed during in vitro refolding of unfolded proteins (194). Time will tell whether other proteins that are extended in their functional conformation are using a similar pathway toward the native state.

Disulfide-bond formation, reduction and isomerization are catalyzed by thiol-disulfide oxidoreductases of the PDI family (Figure 1). Comprising around 20 human members (195), these enzymes play important roles during folding (and degradation) of many proteins. PDIs contain a Cys-Xaa-Xaa-Cys active-site motif embedded in domains with a thioredoxin-like fold (196). In the oxidized state, the active site catalyzes substrate oxidation by disulfide exchange, i.e. the active-site disulfide is simply transferred to the substrate. In the reduced state, PDIs catalyze reduction and isomerization (197). The latter type of reaction may also occur through consecutive rounds of reduction and oxidation (198).

During disulfide exchange, a mixed-disulfide intermediate forms between enzyme and substrate (183). These transient species are inherently difficult to trap in living cells. In a seminal study from the Helenius laboratory, it was demonstrated that PDI and its close homologue, ERp57, co-translationally form mixed-disulfide complexes with Semliki Forest virus (SFV) glycoproteins (199). This study was the first to trap PDI family members with growing nascent chains in the process of oxidative folding. Moreover, the data indicated that both PDI and ERp57 also formed mixed disulfides with the full-length SFV glycoproteins and catalyzed disulfide isomerization in their substrates. Finally, this work demonstrated that ERp57 and SFV glycoproteins existed in a ternary complex with the lectin chaperones CNX and CRT (see below and 76), underscoring the function of ERp57 as a co-chaperone for CNX and CRT especially dedicated to glycoprotein folding (200) (Figure 1). The fact that cells devoid of ERp57 can still fold SFV glycoproteins efficiently was found to rely on replacement of ERp57 with ERp72 (another PDI family member) (172), indicating redundancy among ER oxidoreductases (201).

Upon substrate oxidation, active-site cysteines are left in the reduced state and must be recycled to the disulfide state. Oxidation of PDI by the Erol oxidase constitutes the most important reoxidation pathway, but in recent years it has become clear that several additional such pathways exist (202). For instance, $\mathrm{H}_{2} \mathrm{O}_{2}$ can support oxidative folding facilitated by peroxiredoxin 4 in cells devoid of Ero1 (203). While PDI is the primary cellular substrate of Ero1 (204), it has been shown that PDI family members can exchange disulfides among each other $(204,205)$, abolishing a requirement for all enzymes to become directly oxidized by Ero1 (or reduced by a potential ER-localized reductase, as discussed below).

Given the importance of disulfide isomerization for correct folding, it is crucial for the cell to also ensure that a fraction of active-site cysteines in PDIs are maintained in the reduced state. For instance, recent work has demonstrated that the PDI family member ERdj5 (which is also a J protein that stimulates BiP's ATPase activity) functions to reduce non-native disulfides during folding of the LDLR (206). The exact mechanism by which active-site cysteines in PDIs are kept in the reduced state is unknown, but glutathione likely plays a role in balancing ER redox conditions through reaction with the active sites of PDI family members (207). In addition, an as yet undiscovered reductive pathway coupled to NADPH as the electron donor could also exist (208). In another recent exciting development in this field, it was shown that oxidative folding of, e.g. LDLR proceeds through two phases with differential requirements for oxygen (209). In the initial rapid formation of disulfide bonds, oxygen was shown to be dispensable, whereas post-translational isomerization and dithiol oxidation were dependent on oxygen. These findings indicate that electron acceptors other than molecular oxygen can support oxidative folding in the initial phase of disulfide-bond formation.

\section{$\mathrm{N}$-Linked Glycosylation}

$\mathrm{N}$-glycans are added to the asparagine residue in a simple acceptor sequence (the 'sequon'), which is typically 
Asn-Xaa-Ser/Thr (where Xaa can be any amino acid residue except proline). The $\mathrm{Glc}_{3} \mathrm{Man}_{9} \mathrm{GlCNAc}_{2}$ core oligosaccharide (76) contains three branches, and is transferred from a lipid-linked precursor onto the polypeptide chain by the oligosaccharyltransferase. This enzyme complex essentially comes in two flavors: one contains the catalytic STT3A subunit and is associated with the translocon to perform co-translational glycosylation, whereas the other - containing the STT3B isoform-glycosylates acceptor sites skipped by STT3A (e.g. to carry out post-translational glycosylation) (210).

The addition of N-linked glycans plays a key role in ER protein folding (211), mainly through their interaction with the lectin chaperones CNX and CRT, which positively affects glycoprotein folding efficiency (Figure 1). However, N-glycans also possess intrinsic physicochemical properties that accelerate folding, enhance thermodynamic stability and decrease aggregation propensity of proteins (reviewed in 212).

As detailed elsewhere in this issue by Hebert and coworkers (76), the homologous CNX (membrane-bound) and CRT (soluble) bind mono-glucosylated $\left(\mathrm{Glc}_{1} \mathrm{Man}_{9} \mathrm{GlCNAc}_{2}\right)$ trimming intermediates of the core glycan to assist co- and post-translational folding of a large variety of $\mathrm{N}$-glycosylated proteins (88). Upon release from CNX/CRT, substrates can exit the ER if they are correctly folded. Alternatively, they rebind CNX and/or CRT, which allows them another chance to fold while ensuring ER retention and prevention of aggregation. In this so-called CNX/CRT cycle, binding to and release from CNX and CRT are controlled by independently acting enzymes that modify the $\mathrm{N}$-glycan structure. While bound by either lectin chaperone, the substrate glycoprotein is exposed to the associated co-chaperone ERp57 that facilitates disulfide-bond formation (213). Terminally misfolded glycoproteins are degraded by the ERAD pathway in a process that is also controlled by the structure of the N-linked glycan (73). Overall, CNX and CRT binding slows down glycoprotein folding kinetics, prevents premature ER exit and increases folding efficiency.

Recently, another ER-resident lectin was identified, malectin, which binds to terminally glucosylated oligosaccharides in vitro $(214,215)$, leading to the hypothesis that it may participate in the CNX/CRT cycle. Molinari and coworkers demonstrated, however, that malectin exhibits different substrate-binding affinities and kinetics than CNX, with a preference for misfolded conformers of influenza virus HA (216). This, and the findings that malectin expression is ER-stress sensitive, and its overexpression interferes with protein secretion, points to a putative role in binding and retention of misfolded glycoproteins in the ER (216).

The importance of $\mathrm{N}$-glycans for glycoprotein folding, assembly and secretion is well documented from numerous investigations (217). Given the many positive effects of $\mathrm{N}$-glycosylation for folding and stability, it can be difficult to determine exactly the underlying mechanism of deleterious effects of deleting $\mathrm{N}$-glycosylation sites in specific proteins. However, chemical inhibitors of glycoprotein interaction with CNX and CRT exist, which completely inactivate the CNX/CRT cycle, while maintaining the $\mathrm{N}$-glycan. In addition, knockout cell lines are available for each protein (218-220).

Here, we will draw attention to select examples of how $\mathrm{N}$-glycosylation influences protein folding and assembly to illustrate the versatility of this modification. It is clear that the position of the $\mathrm{N}$-glycan can determine chaperone selection during folding (55). In an important study from the Helenius laboratory, it was shown that the position of the first $\mathrm{N}$-glycan in the polypeptide chain governs the preferred nascent chain interactions with CNX and/or CRT over BiP (221). Overall, the data indicated that the presence of an $\mathrm{N}$-glycan within the first 50 amino acid residues dictates interaction with CNX/CRT, while BiP first binds the nascent chain in the absence of such $\mathrm{N}$-terminally placed $\mathrm{N}$-glycans. On the other hand, the role of BiP during translocation may still allow an even earlier transient interaction with BiP. When employing inhibitors of the CNX/CRT interaction, glycoproteins normally interacting with CNX and/or CRT instead will bind $\mathrm{BiP}$, demonstrating redundancy among the two chaperone systems $(195,222-224)$. A similar finding has recently been published for a disease-causing mutant of fibulin-3, in which N-glycosylation can 'mask' a binding site for Grp94 that is first efficiently exposed when an N-glycan important for CNX/CRT interaction is removed (225). 
This work also demonstrated that mutation of a particular $\mathrm{N}$-glycan important for CNX/CRT interaction selectively conferred negative effects, e.g. increased cellular aggregation and degradation, to the disease-causing mutant when compared with the wild-type protein.

It has also become apparent that $\mathrm{N}$-glycans present on the same polypeptide chain are not equivalent. Thus, mutational analysis has shown that individual glycans differentially influence the rates and efficiencies of folding, oligomerization and secretion; CNX versus CRT binding; and cellular stability (226-234). Importantly, as detailed in the following section, $\mathrm{N}$-glycosylation also critically influences folding through its close connection with disulfide-bond formation.

\section{Interplay Between N-Glycosylation and Disulfide-Bond Formation}

As N-glycosylation and disulfide-bond formation often occur co-translationally, and since many proteins comprise a number of both these modifications, it is only natural that these two processes are intricately connected during folding (235). These connections have been elegantly explored in the Helenius laboratory using a pulse-chase/immunoprecipitation approach in combination with 2D SDS-PAGE (178). As detailed in Box 1, this method can monitor both co- and post-translational $\mathrm{N}$-glycosylation and disulfide-bond formation. When applied to study influenza virus HA folding, the results showed that the formation of disulfide bonds was not a strictly coordinated event in all polypeptide chains, as specific disulfides would form either during or after complete translation of the protein (178). Moreover, it also became clear that inhibitors of $\mathrm{N}$-glycosylation or CNX/CRT interaction perturbed proper disulfide-bond formation. Indeed, when deprived of the interaction with ERp57, certain glycoproteins fail to form correct disulfide bonds $(172,236)$, and from mutational studies it is clear that removal of sites for $\mathrm{N}$-glycosylation can perturb disulfide-bond formation (230-232). Individual $\mathrm{N}$-glycans have been suggested to be positioned close to cysteine residues that need to shield - through interaction of the nearby glycan with CNX or CRT - from non-productive (intermolecular) disulfide-bond formation (55).
The majority of sites for $\mathrm{N}$-glycan addition are present in predicted flexible regions, such as loops (237). At the same time, an extended and non-restricted conformation of the polypeptide chain is preferred by OST (238). Therefore, these quite recent data predict that protein folding could compete with $\mathrm{N}$-glycosylation. Indeed, previous studies show this to be the case. Investigations in Saccharomyces cerevisiae using Carboxypeptidase $\mathrm{Y}$ and in a cell-free system as well as mammalian cells using tissue-type plasminogen activator have collectively shown that conditions that favor folding result in less efficient glycosylation (239-241). Similarly, in cells with a truncated core $\mathrm{N}$-glycan, glycosylation is slow due to lower OST affinity and proteins are hypoglycosylated (242). The same studies show that conditions that prevent folding - e.g. in the presence of a reducing agent to counteract disulfide-bond formation - lead to increased glycosylation at sequons only partially utilized under normal conditions. In general, when perturbing either of the two processes, $\mathrm{N}$-glycosylation or disulfide-bond formation, the other is likely influenced as well.

The intimate connection between N-glycosylation and disulfide-bond formation is underscored by the finding that two subunits of the OST, the paralogs MagT1 and TUSC3, are thiol-disulfide oxidoreductases required for efficient N-glycosylation of acceptor sites located close to cysteine residues (e.g. NCS/T sequons or sites bracketed by a disulfide bond). The function of these two proteins was established initially for the yeast orthologs Ost3p and Ost6p (243), and supported by structural and biochemical studies on TUSC3 (74). These investigations have shown that the two proteins localize to the ER membrane and contain a thioredoxin-like domain with an embedded typical Cys-Xaa-Xaa-Cys active-site motif. The reduction potential of the active-site disulfide is highly reducing, showing that the two cysteines prefer the oxidized state, as confirmed for MagT1 (244). Based on the biochemical and structural work, a model was suggested whereby MagT1/TUSC3 (Ost3p/Ost6p) forms a transient mixed disulfide with certain glycoproteins $(74,243)$. The mixed disulfide arises as a result of a nucleophilic attack by a cysteine thiolate from the glycoprotein on the active-site disulfide of the oxidoreductase. This intermolecular covalent interaction is proposed to stall glycoprotein folding by delaying disulfide-bond formation, which 
in turn will increase glycosylation efficiency on nearby sequons.

This model was recently corroborated and extended to identify the types of substrates preferred by MagT1 in HeLa cells, which do not express TUSC3 (244). Here, it was shown that MagT1 associates only with OST complexes containing the STT3B isoform, and thus is involved in glycosylation of substrates skipped by STT3A during translation. Based on the analysis of a variety of acceptor sites, the main class of substrates for MagT1-dependent glycosylation was proposed to be those containing cysteines involved in disulfide-bond formation flanking the acceptor site, as in, for example, factor VII (244). In essence, the slowdown of protein folding resulting from MagT1 binding to substrate glycoproteins increases the glycosylation efficiency, a finding completely in line with the results demonstrating competition between folding and glycosylation.

\section{Other Protein Modifications}

While the protein modifications mentioned above are crucial for folding of most proteins synthesized in the ER, other modifications are directed toward a smaller subset of proteins, or are less well understood.

Fatty acylation occurs in the cytosol, on both cytosolic proteins and the cytosolic tails/domains of transmembrane proteins, and comes in two main flavors: $\mathrm{N}$-myristoylation and S-acylation.

$\mathrm{N}$-myristoylation is the attachment of myristate, a 14-carbon saturated fatty acid to the $\mathrm{N}$-terminal glycine of certain eukaryotic proteins. Although normally considered to be a post-translational modification, myristoylation occurs co-translationally after removal of the leader methionine to expose an N-terminal glycine $(245,246)$. While myristoylation has been characterized mainly as a modification of cytoplasmic proteins, viral membrane proteins can be $\mathrm{N}$-myristoylated as well: for the large envelope protein of hepatitis B virus (HBV L), a polytopic membrane protein, myristoylation is essential for viral infectivity and intracellular retention $(247,248)$. This permanent modification may tether the $\mathrm{N}$-terminus of a protein to the membrane, which is likely to affect its folding during translation.
S-acylation of proteins is the post-translational attachment of long-chain fatty acids, mostly palmitate, to cysteine residues. Palmitoylation is unique among lipid modifications because it is a reversible modification that allows it to play a role in regulation and fine-tuning of protein function similar to ubiquitination and phosphorylation (249). Palmitoylation also occurs on the cytoplasmic tails or domains of transmembrane proteins, such as GPCRs (250), intramembrane proteases $(251,252)$, PDI family members (253) and chaperones $(253,254)$. CFTR (255), influenza virus HA (256) and LRP6 (257) need palmitoylation to leave the ER. Especially for multimembrane-spanning proteins, such as ion channels with less hydrophobic transmembrane helices, fatty acylation may well be essential for folding and domain assembly to the native, functional conformation.

A recent review (258) pointed out that the cellular and functional consequences of palmitoylation are not necessarily direct when it comes to protein folding, but rather caused by processes such as conformational changes of transmembrane domains, regulation of membrane domain association and protein complex formation. Recent examples from the literature include the importance of palmitoylation for inositol 1,4,5-trisphosphate receptor (IP3R) function (259), which in turn influences ER $\mathrm{Ca}^{2+}$ flux and thereby ER protein folding, and for modulation of ER subdomain localization of the transmembrane PDI family member TMX (253). Moreover, the palmitoylation status of CNX can determine its association with the ribosome-translocon complex (260) and SERCA2b (254), which directly influences glycoprotein folding and $\mathrm{ER} \mathrm{Ca}^{2+}$ content, respectively. These examples demonstrate that regulation of ER protein folding can be a secondary consequence of modification of the protein folding machinery. Whether this excludes a direct effect on folding remains an open question, as the processes mentioned above all involve conformational changes, which by definition influence folding.

Proline hydroxylation has long been known and recognized to be important for protein folding and stability in the ER. At the same time, the primary substrate of proline hydroxylation, procollagen, is a 'showcase' for the interdependence between post-translational modification and protein folding. Notably, procollagen folding is assisted by 
more than 20 chaperones, folding enzymes and enzymes that catalyze procollagen modification (261).

Procollagen is extensively proline hydroxylated, which influences the conformation of the polypeptide backbone to allow more efficient triple-helix formation. At the same time, proline hydroxylation has been shown in vitro to be essential for stability of the triple helix at physiological temperatures (262). A prerequisite for formation of the triple-helix structure is the isomerization of all prolines to the trans conformation $(263,264)$. Given that certain prolyl hydroxylases and PPIases are found in complex (265), the modifications catalyzed by these types of enzymes likely work in concert to generate thermostable procollagen in cells (261). The exact role in vivo of the PPIases СypB and FKBP65 during collagen biosynthesis is unclear, as both are found in complex with other factors crucial for collagen folding. СурB has been identified in complex with prolyl 3-hydroxylase 1 and cartilage-associated protein (261) and as a heterodimer with lysine hydroxylase 1 (261). Upon triple-helix formation, the properly folded procollagen molecule is no longer a substrate for prolyl (and lysyl) hydroxylation (261). At this point, the collagen-specific chaperone Hsp47 binds procollagen to prevent its premature association into bundles and to promote its ER-to-Golgi transport (266).

Prolyl hydroxylase is known to require ascorbate (vitamin C), and scurvy leads to misfolding and ER retention of procollagens. Recent evidence provides an unexpected link between proline hydroxylation and oxidative protein folding. Thus, conditions that lead to excess production of $\mathrm{H}_{2} \mathrm{O}_{2}$ in the ER were found to deplete lumenal ascorbate by oxidative inactivation, which in turn damaged proline hydroxylation of procollagen and led to an unconventional type of scurvy $(267,268)$.

In addition to the known substrates (pro)collagens, the collagen-like adiponectins (269), conotoxins (270) and some cell-wall proteins in plants, other substrates for prolyl hydroxylases are bound to be identified. The same is true for lysine hydroxylation, which has been studied sparsely and is also connected to procollagen and conotoxin biosynthesis. Interesting is the secondary modification of hydroxylysine, which can be glycosylated thereby changing the character of the nearby (collagen) polypeptide chain even more $(271,272)$.

Unlike proline and lysine hydroxylation, acetylation of lysine has only recently been found in the ER (273). The modification occurs on several ER-transiting and ER-resident proteins, including chaperones and enzymes involved in protein modification and folding (274), and two involved acetyltransferases are known (275). The exact function of lysine acetylation is still not clear, but it may well serve distinct purposes for ER-transiting versus ER-resident proteins. Lysine acetylation in newly synthesized proteins seems to take place on correctly folded proteins with non-acetylated species being subject to degradation in a post-ER compartment by the PCSK9 protease (276), whereas modification of ER-resident proteins has been speculated to influence their function and/or activity (277). Disruption of ER lysine acetylation leads to cell death and is associated with serious human diseases $(277,278)$. Many questions concerning lysine acetylation in the ER remain unanswered (277), e.g. how acetyltransferases distinguish substrates from non-substrates, and it will be intriguing to follow this topic in the future.

\section{Concluding Remarks}

With about a third of all human proteins being synthesized in the ER, correct protein biogenesis in this organelle is of crucial importance to cellular and organismal function. As illustrated in this review, ER protein folding and assembly are carefully orchestrated processes that most often require the interplay between several chaperones and folding factors as well as different kinds of co- and post-translational modifications. Such modifications contribute directly to increased protein solubility and stability, but also serve important purposes in directing the folding process by recruitment of chaperones. Considering the complexity involved in folding and assembly of, e.g. procollagen or hetero-oligomeric complexes of membrane-spanning proteins each containing a variety of disulfide bonds and $\mathrm{N}$-glycans, and the many potential pitfalls encountered during this process, it is astounding that these processes work quite efficiently for many proteins.

The newly synthesized protein will dictate and direct some of these processes because during folding, driven by its 
own internal forces, the protein will transiently expose and shield modification sites as well as chaperone and folding-enzyme interaction sites. External regulation is imposed by the collective network of molecular folding factors, local activity of which is controlled by co-chaperones, chaperone modifications as well as the folding protein, as it for instance stimulates ATP hydrolysis in BiP. Overall, differential regulation of components of the chaperone network, such as through ER stress responses, at the transcriptional, translational and post-translational levels aims to produce, for each cell at any point in time, the optimal set of chaperones, folding enzymes and folding conditions in the ER that ensure a healthy life.

\section{Acknowledgments}

We would like to thank Dr Ari Helenius for his major contributions to the field of protein folding in the ER, as well as for his inspiring and outstanding supervision. We thank Mr Doron Gollnast for his contributions to Figure 2 and for his comments on the manuscript text.

\section{References}

1. O'Brien EP, Ciryam P, Vendruscolo M, Dobson CM. Understanding the influence of codon translation rates on cotranslational protein folding. Acc Chem Res 2014;47:1536-1544.

2. Zhang $G$, Ignatova Z. Folding at the birth of the nascent chain: coordinating translation with co-translational folding. Curr Opin Struct Biol 2011;21:25-31.

3. Bhushan S, Gartmann M, Halic M, Armache JP, Jarasch A, Mielke T, Berninghausen O, Wilson DN, Beckmann R. alpha-Helical nascent polypeptide chains visualized within distinct regions of the ribosomal exit tunnel. Nat Struct Mol Biol 2010;17:313-317.

4. Etchells SA, Meyer AS, Yam AY, Roobol A, Miao Y, Shao Y, Carden MJ, Skach WR, Frydman J, Johnson AE. The cotranslational contacts between ribosome-bound nascent polypeptides and the subunits of the hetero-oligomeric chaperonin TRiC probed by photocross-linking. J Biol Chem 2005;280:28118-28126.

5. Tu LW, Deutsch C. A folding zone in the ribosomal exit tunnel for Kv1.3 helix formation. J Mol Biol 2010;396:1346-1360.

6. Woolhead CA, McCormick PJ, Johnson AE. Nascent membrane and secretory proteins differ in FRET-detected folding far inside the ribosome and in their exposure to ribosomal proteins. Cell 2004;116:725-736.

7. Nilsson $O B$, Hedman $R$, Marino J, Wickles $S$, Bischoff $L$, Johansson M, Muller-Lucks A, Trovato F, Puglisi JD, O'Brien EP, Beckmann R, von Heijne $G$. Cotranslational protein folding inside the ribosome exit tunnel. Cell Rep 2015;12:1533-1540.

8. Lu J, Deutsch C. Regional discrimination and propagation of local rearrangements along the ribosomal exit tunnel. J Mol Biol 2014;426:4061-4073.
9. Lu J, Hua Z, Kobertz WR, Deutsch C. Nascent peptide side chains induce rearrangements in distinct locations of the ribosomal tunnel. J Mol Biol 2011;411:499-510.

10. Nakatogawa $H$, Ito K. The ribosomal exit tunnel functions as a discriminating gate. Cell 2002;108:629-636.

11. Yap MN, Bernstein HD. The plasticity of a translation arrest motif yields insights into nascent polypeptide recognition inside the ribosome tunnel. Mol Cell 2009;34:201-211.

12. Berndt $U$, Oellerer $S$, Zhang $Y$, Johnson AE, Rospert S. A signal-anchor sequence stimulates signal recognition particle binding to ribosomes from inside the exit tunnel. Proc Natl Acad Sci USA 2009;106:1398-1403.

13. Devaraneni PK, Conti B, Matsumura Y, Yang Z, Johnson AE, Skach WR. Stepwise insertion and inversion of a type II signal anchor sequence in the ribosome-Sec61 translocon complex. Cell 2011;146:134-147.

14. Liao S, Lin J, Do H, Johnson AE. Both lumenal and cytosolic gating of the aqueous ER translocon pore are regulated from inside the ribosome during membrane protein integration. Cell 1997;90:31-41.

15. Lin PJ, Jongsma CG, Liao S, Johnson AE. Transmembrane segments of nascent polytopic membrane proteins control cytosol/ER targeting during membrane integration. J Cell Biol 2011;195:41-54.

16. Lakkaraju AK, Mary C, Scherrer A, Johnson AE, Strub K. SRP keeps polypeptides translocation-competent by slowing translation to match limiting ER-targeting sites. Cell 2008;133:440-451.

17. van der Zand A, Braakman I, Tabak HF. Peroxisomal membrane proteins insert into the endoplasmic reticulum. Mol Biol Cell 2010;21:2057-2065.

18. Gamerdinger M, Hanebuth MA, Frickey T, Deuerling E. The principle of antagonism ensures protein targeting specificity at the endoplasmic reticulum. Science 2015;348:201-207.

19. Gogala M, Becker T, Beatrix B, Armache JP, Barrio-Garcia C, Berninghausen 0, Beckmann R. Structures of the Sec61 complex engaged in nascent peptide translocation or membrane insertion. Nature 2014;506:107-110.

20. Halic M, Becker T, Pool MR, Spahn CM, Grassucci RA, Frank J, Beckmann R. Structure of the signal recognition particle interacting with the elongation-arrested ribosome. Nature 2004;427: 808-814.

21. Chen $W$, Helenius $A$. Role of ribosome and translocon complex during folding of influenza hemagglutinin in the endoplasmic reticulum of living cells. Mol Biol Cell 2000;11:765-772.

22. Kowarik M, Kung S, Martoglio B, Helenius A. Protein folding during cotranslational translocation in the endoplasmic reticulum. Mol Cell 2002;10:769-778.

23. Braakman I, Hebert DN. Protein folding in the endoplasmic reticulum. Cold Spring Harb Perspect Biol 2013;5:a013201.

24. Braakman I, Hoover-Litty H, Wagner KR, Helenius A. Folding of influenza hemagglutinin in the endoplasmic reticulum. J Cell Biol 1991;114:401-411.

25. Chen J, Lee KH, Steinhauer DA, Stevens DJ, Skehel JJ, Wiley DC. Structure of the hemagglutinin precursor cleavage site, a 
determinant of influenza pathogenicity and the origin of the labile conformation. Cell 1998;95:409-417.

26. Sauter NK, Hanson JE, Glick GD, Brown JH, Crowther RL, Park SJ, Skehel JJ, Wiley DC. Binding of influenza virus hemagglutinin to analogs of its cell-surface receptor, sialic acid: analysis by proton nuclear magnetic resonance spectroscopy and X-ray crystallography. Biochemistry 1992;31:9609-9621.

27. Sun X, Li Q, Wu Y, Wang M, Liu Y, Qi J, Vavricka CJ, Gao GF. Structure of influenza virus N7: the last piece of the neuraminidase "jigsaw" puzzle. J Virol 2014;88:9197-9207.

28. Pancera M, Zhou T, Druz A, Georgiev IS, Soto C, Gorman J, Huang J, Acharya P, Chuang GY, Ofek G, Stewart-Jones GB, Stuckey J, Bailer RT, Joyce MG, Louder MK, et al. Structure and immune recognition of trimeric pre-fusion HIV-1 Env. Nature 2014;514:455-461.

29. Kozlov G, Bastos-Aristizabal S, Maattanen P, Rosenauer A, Zheng F, Killikelly A, Trempe JF, Thomas DY, Gehring K. Structural basis of cyclophilin B binding by the calnexin/calreticulin P-domain. J Biol Chem 2010;285:35551-35557.

30. Hegde RS, Voigt S, Lingappa VR. Regulation of protein topology by trans-acting factors at the endoplasmic reticulum. Mol Cell 1998:2:85-91.

31. Shaffer KL, Sharma A, Snapp EL, Hegde RS. Regulation of protein compartmentalization expands the diversity of protein function. Dev Cell 2005;9:545-554.

32. Beauchamp E, Tekpli X, Marteil G, Lagadic-Gossmann D, Legrand P, Rioux V. N-Myristoylation targets dihydroceramide Delta4-desaturase 1 to mitochondria: partial involvement in the apoptotic effect of myristic acid. Biochimie 2009;91:1411-1419.

33. Borgese N, Aggujaro D, Carrera P, Pietrini G, Bassetti M. A role for $\mathrm{N}$-myristoylation in protein targeting: $\mathrm{NADH}$-cytochrome b5 reductase requires myristic acid for association with outer mitochondrial but not ER membranes. J Cell Biol 1996;135(6 Pt 1):1501-1513.

34. von Heijne $\mathrm{G}$. Membrane protein structure prediction. Hydrophobicity analysis and the positive-inside rule. J Mol Biol 1992;225:487-494.

35. Shaw AS, Rottier PJ, Rose JK. Evidence for the loop model of signal-sequence insertion into the endoplasmic reticulum. Proc Natl Acad Sci USA 1988;85:7592-7596.

36. Blobel G, Dobberstein B. Transfer of proteins across membranes. I. Presence of proteolytically processed and unprocessed nascent immunoglobulin light chains on membrane-bound ribosomes of murine myeloma. J Cell Biol 1975;67:835-851.

37. Jackson RC, Blobel G. Post-translational cleavage of presecretory proteins with an extract of rough microsomes from dog pancreas containing signal peptidase activity. Proc Natl Acad Sci USA 1977;74:5598-5602.

38. Petersen TN, Brunak S, von Heijne G, Nielsen H. SignalP 4.0: discriminating signal peptides from transmembrane regions. Nat Methods 2011;8:785-786.

39. Nilsson I, von Heijne G. A signal peptide with a proline next to the cleavage site inhibits leader peptidase when present in a sec-independent protein. FEBS Lett 1992;299:243-246.
40. Cui J, Chen W, Sun J, Guo H, Madley R, Xiong Y, Pan X, Wang H, Tai AW, Weiss MA, Arvan P, Liu M. Competitive inhibition of the endoplasmic reticulum signal peptidase by non-cleavable mutant preprotein cargos. J Biol Chem 2015;290:28131-28140.

41. Li Y, Luo L, Thomas DY, Kang CY. The HIV-1 Env protein signal sequence retards its cleavage and down-regulates the glycoprotein folding. Virology 2000;272:417-428.

42. Rehm A, Stern P, Ploegh HL, Tortorella D. Signal peptide cleavage of a type I membrane protein, HCMV US11, is dependent on its membrane anchor. EMBO J 2001;20:1573-1582.

43. Tamura T, Cormier JH, Hebert DN. Characterization of early EDEM1 protein maturation events and their functional implications. J Biol Chem 2011;286:24906-24915.

44. Land A, Zonneveld D, Braakman I. Folding of HIV-1 envelope glycoprotein involves extensive isomerization of disulfide bonds and conformation-dependent leader peptide cleavage. FASEB J 2003;17:1058-1067.

45. Sipos $L$, von Heijne $G$. Predicting the topology of eukaryotic membrane proteins. Eur J Biochem 1993;213:1333-1340.

46. Symoens S, Malfait F, Renard M, Andre J, Hausser I, Loeys B, Coucke $P$, De Paepe A. COL5A1 signal peptide mutations interfere with protein secretion and cause classic Ehlers-Danlos syndrome. Hum Mutat 2009;30:E395-E403.

47. Datta R, Waheed A, Shah GN, Sly WS. Signal sequence mutation in autosomal dominant form of hypoparathyroidism induces apoptosis that is corrected by a chemical chaperone. Proc Natl Acad Sci USA 2007;104:19989-19994.

48. Ito M, Oiso Y, Murase T, Kondo K, Saito H, Chinzei T, Racchi M, Lively MO. Possible involvement of inefficient cleavage of preprovasopressin by signal peptidase as a cause for familial central diabetes insipidus. J Clin Invest 1993;91:2565-2571.

49. Racchi M, Watzke HH, High KA, Lively MO. Human coagulation factor $X$ deficiency caused by a mutant signal peptide that blocks cleavage by signal peptidase but not targeting and translocation to the endoplasmic reticulum. J Biol Chem 1993;268:5735-5740.

50. Whittington HA, Freeburn RW, Godinho SI, Egan J, Haider Y, Millar $A B$. Analysis of an IL-10 polymorphism in idiopathic pulmonary fibrosis. Genes Immun 2003:4:258-264.

51. Hughes AE, Ralston SH, Marken J, Bell C, MacPherson H, Wallace RG, van Hul W, Whyte MP, Nakatsuka K, Hovy L, Anderson DM. Mutations in TNFRSF11A, affecting the signal peptide of RANK, cause familial expansile osteolysis. Nat Genet 2000;24:45-48.

52. Piersma D, Berns EM, Verhoef-Post M, Uitterlinden AG, Braakman I, Pols HA, Themmen AP. A common polymorphism renders the luteinizing hormone receptor protein more active by improving signal peptide function and predicts adverse outcome in breast cancer patients. J Clin Endocrinol Metab 2006;91:1470-1476.

53. Karaplis AC, Lim SK, Baba H, Arnold A, Kronenberg HM. Inefficient membrane targeting, translocation, and proteolytic processing by signal peptidase of a mutant preproparathyroid hormone protein. J Biol Chem 1995;270:1629-1635. 
54. Rutkowski DT, Ott CM, Polansky JR, Lingappa VR. Signal sequences initiate the pathway of maturation in the endoplasmic reticulum lumen. J Biol Chem 2003;278:30365-30372.

55. Daniels R, Kurowski B, Johnson AE, Hebert DN. N-linked glycans direct the cotranslational folding pathway of influenza hemagglutinin. Mol Cell 2003;11:79-90.

56. Martoglio B, Dobberstein B. Signal sequences: more than just greasy peptides. Trends Cell Biol 1998;8:410-415.

57. Boulay F, Doms RW, Webster RG, Helenius A. Posttranslational oligomerization and cooperative acid activation of mixed influenza hemagglutinin trimers. J Cell Biol 1988;106:629-639.

58. Nicholls CD, McLure KG, Shields MA, Lee PW. Biogenesis of p53 involves cotranslational dimerization of monomers and posttranslational dimerization of dimers. Implications on the dominant negative effect. J Biol Chem 2002;277:12937-12945.

59. Shieh YW, Minguez P, Bork P, Auburger JJ, Guilbride DL, Kramer G, Bukau B. Operon structure and cotranslational subunit association direct protein assembly in bacteria. Science 2015;350:678-680.

60. Wells JN, Bergendahl LT, Marsh JA. Co-translational assembly of protein complexes. Biochem Soc Trans 2015;43:1221-1226.

61. Copeland CS, Doms RW, Bolzau EM, Webster RG, Helenius A. Assembly of influenza hemagglutinin trimers and its role in intracellular transport. J Cell Biol 1986;103:1179-1191.

62. Crise B, Ruusala A, Zagouras P, Shaw A, Rose JK. Oligomerization of glycolipid-anchored and soluble forms of the vesicular stomatitis virus glycoprotein. J Virol 1989;63:5328-5333.

63. Kreis TE, Lodish HF. Oligomerization is essential for transport of vesicular stomatitis viral glycoprotein to the cell surface. Cell 1986;46:929-937.

64. Lyles DS, Varela VA, Parce JW. Dynamic nature of the quaternary structure of the vesicular stomatitis virus envelope glycoprotein. Biochemistry 1990;29:2442-2449.

65. Bergman LW, Kuehl WM. Co-translational modification of nascent immunoglobulin heavy and light chains. J Supramol Struct 1979;11:9-24.

66. Bergman LW, Kuehl WM. Formation of intermolecular disulfide bonds on nascent immunoglobulin polypeptides. J Biol Chem 1979;254:5690-5694.

67. Hendershot L, Bole D, Kearney JF. The role of immunoglobulin heavy chain binding protein in immunoglobulin transport. Immunol Today 1987;8:111-114.

68. Hendershot LM. Immunoglobulin heavy chain and binding protein complexes are dissociated in vivo by light chain addition. J Cell Biol 1990;111:829-837.

69. Lee YK, Brewer JW, Hellman R, Hendershot LM. BiP and immunoglobulin light chain cooperate to control the folding of heavy chain and ensure the fidelity of immunoglobulin assembly. Mol Biol Cell 1999;10:2209-2219.

70. Vanhove M, Usherwood YK, Hendershot LM. Unassembled Ig heavy chains do not cycle from BiP in vivo but require light chains to trigger their release. Immunity 2001;15:105-114.

71. Feige MJ, Behnke J, Mittag T, Hendershot LM. Dimerization-dependent folding underlies assembly control of the clonotypic alphabetaT cell receptor chains. J Biol Chem 2015;290:26821-26831.

72. Feige MJ, Hendershot LM. Quality control of integral membrane proteins by assembly-dependent membrane integration. Mol Cell 2013;51:297-309.

73. Pisoni GB, Molinari M. Five questions (with their answers) on ER-associated degradation. Traffic 2016. doi:10.1111/tra.12373.

74. Mohorko E, Owen RL, Malojcic G, Brozzo MS, Aebi M, Glockshuber R. Structural basis of substrate specificity of human oligosaccharyl transferase subunit N33/Tusc3 and its role in regulating protein N-glycosylation. Structure 2014;22:590-601.

75. Pfeffer S, Dudek J, Gogala M, Schorr S, Linxweiler J, Lang S, Becker $T$, Beckmann R, Zimmermann R, Forster F. Structure of the mammalian oligosaccharyl-transferase complex in the native ER protein translocon. Nat Commun 2014;5:3072.

76. Lamriben L, Graham JB, Adams BM, Hebert DN. N-glycan based ER molecular chaperone and protein quality control system: the calnexin binding cycle. Traffic 2016. doi:10.1111/tra.12358.

77. Hurtley SM, Helenius A. Protein oligomerization in the endoplasmic reticulum. Annu Rev Cell Biol 1989;5:277-307.

78. Krishna MM, Englander SW. The N-terminal to C-terminal motif in protein folding and function. Proc Natl Acad Sci USA 2005;102:1053-1058.

79. Jansens A, van Duijn E, Braakman I. Coordinated nonvectorial folding in a newly synthesized multidomain protein. Science 2002;298:2401-2403.

80. Hou B, Lin PJ, Johnson AE. Membrane protein TM segments are retained at the translocon during integration until the nascent chain cues FRET-detected release into bulk lipid. Mol Cell 2012;48:398-408.

81. Pitonzo D, Yang Z, Matsumura Y, Johnson AE, Skach WR. Sequence-specific retention and regulated integration of a nascent membrane protein by the endoplasmic reticulum Sec61 translocon. Mol Biol Cell 2009;20:685-698.

82. Tamborero S, Vilar M, Martinez-Gil L, Johnson AE, Mingarro I. Membrane insertion and topology of the translocating chain-associating membrane protein (TRAM). J Mol Biol 2011;406:571-582.

83. Buck TM, Wagner J, Grund S, Skach WR. A novel tripartite motif involved in aquaporin topogenesis, monomer folding and tetramerization. Nat Struct Mol Biol 2007;14:762-769.

84. Patterson MA, Bandyopadhyay A, Devaraneni PK, Woodward J, Rooney L, Yang Z, Skach WR. The ribosome-Sec61 translocon complex forms a cytosolically restricted environment for early polytopic membrane protein folding. J Biol Chem 2015;290:28944-28952.

85. Hartl FU, Hayer-Hartl M. Converging concepts of protein folding in vitro and in vivo. Nat Struct Mol Biol 2009;16:574-581.

86. Hendershot LM. The ER function BiP is a master regulator of ER function. Mt Sinai J Med 2004;71:289-297.

87. Marzec M, Eletto D, Argon Y. GRP94: an HSP90-like protein specialized for protein folding and quality control in the endoplasmic reticulum. Biochim Biophys Acta 2012;1823:774-787. 
88. Tannous A, Pisoni GB, Hebert DN, Molinari M. N-linked sugar-regulated protein folding and quality control in the ER. Semin Cell Dev Biol 2015;41:79-89.

89. Simons JF, Ferro-Novick S, Rose MD, Helenius A. BiP/Kar2p serves as a molecular chaperone during carboxypeptidase $Y$ folding in yeast. J Cell Biol 1995;130:41-49.

90. Hurtley SM, Bole DG, Hoover-Litty H, Helenius A, Copeland CS. Interactions of misfolded influenza virus hemagglutinin with binding protein (BiP). J Cell Biol 1989;108:2117-2126.

91. Machamer CE, Doms RW, Bole DG, Helenius A, Rose JK. Heavy chain binding protein recognizes incompletely disulfide-bonded forms of vesicular stomatitis virus $\mathrm{G}$ protein. J Biol Chem 1990;265:6879-6883.

92. Marquardt T, Helenius A. Misfolding and aggregation of newly synthesized proteins in the endoplasmic reticulum. J Cell Biol 1992;117:505-513.

93. Singh I, Doms RW, Wagner KR, Helenius A. Intracellular transport of soluble and membrane-bound glycoproteins: folding, assembly and secretion of anchor-free influenza hemagglutinin. EMBO J 1990;9:631-639.

94. Hammond C, Helenius A. Quality control in the secretory pathway: retention of a misfolded viral membrane glycoprotein involves cycling between the ER, intermediate compartment, and Golgi apparatus. J Cell Biol 1994;126:41-52.

95. Pincus D, Chevalier MW, Aragon T, van Anken E, Vidal SE, El-Samad $\mathrm{H}$, Walter P. BiP binding to the ER-stress sensor Ire1 tunes the homeostatic behavior of the unfolded protein response. PLoS Biol 2010;8:e1000415.

96. Lievremont JP, Rizzuto R, Hendershot L, Meldolesi J. BiP, a major chaperone protein of the endoplasmic reticulum lumen, plays a direct and important role in the storage of the rapidly exchanging pool of $\mathrm{Ca}^{2+}$. J Biol Chem 1997;272:30873-30879.

97. Tiwari S, Askari JA, Humphries MJ, Bulleid NJ. Divalent cations regulate the folding and activation status of integrins during their intracellular trafficking. J Cell Sci 2011;124(Pt 10):1672-1680.

98. Wilcox DA, Wautier JL, Pidard D, Newman PJ. A single amino acid substitution flanking the fourth calcium binding domain of alpha Ilb prevents maturation of the alpha Illb beta 3 integrin complex. J Biol Chem 1994;269:4450-4457.

99. Malby S, Pickering R, Saha S, Smallridge R, Linse S, Downing AK. The first epidermal growth factor-like domain of the low-density lipoprotein receptor contains a noncanonical calcium binding site. Biochemistry 2001;40:2555-2563.

100. Pena F, Jansens A, van Zadelhoff G, Braakman I. Calcium as a crucial cofactor for low density lipoprotein receptor folding in the endoplasmic reticulum. J Biol Chem 2010;285:8656-8664.

101. Luo S, Mao C, Lee B, Lee AS. GRP78/BiP is required for cell proliferation and protecting the inner cell mass from apoptosis during early mouse embryonic development. Mol Cell Biol 2006;26:5688-5697.

102. Paton AW, Beddoe T, Thorpe CM, Whisstock JC, Wilce MC, Rossjohn J, Talbot UM, Paton JC. AB5 subtilase cytotoxin inactivates the endoplasmic reticulum chaperone BiP. Nature 2006;443:548-552.
103. Hendershot LM, Wei JY, Gaut JR, Lawson B, Freiden PJ, Murti KG. In vivo expression of mammalian BiP ATPase mutants causes disruption of the endoplasmic reticulum. Mol Biol Cell 1995;6:283-296.

104. Melnyk A, Rieger H, Zimmermann R. Co-chaperones of the mammalian endoplasmic reticulum. Subcell Biochem 2015;78:179-200.

105. Behnke J, Feige MJ, Hendershot LM. BiP and its nucleotide exchange factors Grp170 and Sil1: mechanisms of action and biological functions. J Mol Biol 2015;427:1589-1608.

106. Bracher A, Verghese J. GrpE, Hsp110/Grp170, HspBP1/Sil1 and BAG domain proteins: nucleotide exchange factors for Hsp70 molecular chaperones. Subcell Biochem 2015;78:1-33.

107. Matlack KE, Misselwitz B, Plath K, Rapoport TA. BiP acts as a molecular ratchet during posttranslational transport of prepro-alpha factor across the ER membrane. Cell 1999;97:553-564.

108. Matlack KE, Plath K, Misselwitz B, Rapoport TA. Protein transport by purified yeast Sec complex and Kar2p without membranes. Science 1997;277:938-941.

109. Haas $I G$, Wabl M. Immunoglobulin heavy chain binding protein. Nature 1983;306:387-389.

110. Feige MJ, Groscurth S, Marcinowski M, Shimizu Y, Kessler $H$, Hendershot LM, Buchner J. An unfolded $\mathrm{CH} 1$ domain controls the assembly and secretion of $\mathrm{IgG}$ antibodies. Mol Cell 2009;34:569-579.

111. Chevalier M, Rhee H, Elguindi EC, Blond SY. Interaction of murine BiP/GRP78 with the DnaJ homologue MTJ1. J Biol Chem 2000;275:19620-19627.

112. Dudek J, Greiner M, Muller A, Hendershot LM, Kopsch K, Nastainczyk W, Zimmermann R. ERj1p has a basic role in protein biogenesis at the endoplasmic reticulum. Nat Struct Mol Biol 2005;12:1008-1014.

113. Jin Y, Awad W, Petrova K, Hendershot LM. Regulated release of ERdj3 from unfolded proteins by BiP. EMBO J 2008;27:2873-2882.

114. Jin $Y$, Zhuang M, Hendershot LM. ERdj3, a luminal ER DnaJ homologue, binds directly to unfolded proteins in the mammalian ER: identification of critical residues. Biochemistry 2009;48:41-49.

115. Guo F, Snapp EL. ERdj3 regulates BiP occupancy in living cells. J Cell Sci 2013;126(Pt 6):1429-1439.

116. Dong M, Bridges JP, Apsley K, Xu Y, Weaver TE. ERdj4 and ERdj5 are required for endoplasmic reticulum-associated protein degradation of misfolded surfactant protein C. Mol Biol Cell 2008;19:2620-2630.

117. Hagiwara M, Maegawa K, Suzuki M, Ushioda R, Araki K, Matsumoto Y, Hoseki J, Nagata K, Inaba K. Structural basis of an ERAD pathway mediated by the ER-resident protein disulfide reductase ERdj5. Mol Cell 2011;41:432-444.

118. Lai CW, Otero JH, Hendershot LM, Snapp E. ERdj4 protein is a soluble endoplasmic reticulum (ER) DnaJ family protein that interacts with ER-associated degradation machinery. J Biol Chem 2012;287:7969-7978.

119. Sekhar A, Rosenzweig R, Bouvignies G, Kay LE. Mapping the conformation of a client protein through the Hsp70 functional cycle. Proc Natl Acad Sci USA 2015;112:10395-10400. 
120. Liu B, Staron M, Hong F, Wu BX, Sun S, Morales C, Crosson CE, Tomlinson S, Kim I, Wu D, Li Z. Essential roles of grp94 in gut homeostasis via chaperoning canonical Wnt pathway. Proc Natl Acad Sci USA 2013;110:6877-6882.

121. Weekes MP, Antrobus R, Talbot S, Hor S, Simecek N, Smith DL, Bloor $S$, Randow F, Lehner PJ. Proteomic plasma membrane profiling reveals an essential role for gp96 in the cell surface expression of LDLR family members, including the LDL receptor and LRP6. J Proteome Res 2012;11:1475-1484.

122. Bloor S, Maelfait J, Krumbach R, Beyaert R, Randow F. Endoplasmic reticulum chaperone gp96 is essential for infection with vesicular stomatitis virus. Proc Natl Acad Sci USA 2010;107:6970-6975.

123. Liu B, Li Z. Endoplasmic reticulum HSP90b1 (gp96, grp94) optimizes B-cell function via chaperoning integrin and TLR but not immunoglobulin. Blood 2008;112:1223-1230.

124. Randow F, Seed B. Endoplasmic reticulum chaperone gp96 is required for innate immunity but not cell viability. Nat Cell Biol 2001;3:891-896.

125. Wu S, Hong F, Gewirth D, Guo B, Liu B, Li Z. The molecular chaperone gp96/GRP94 interacts with Toll-like receptors and integrins via its C-terminal hydrophobic domain. J Biol Chem 2012;287:6735-6742.

126. Melnick J, Aviel S, Argon Y. The endoplasmic reticulum stress protein GRP94, in addition to BiP, associates with unassembled immunoglobulin chains. J Biol Chem 1992;267:21303-21306.

127. Pagetta A, Tramentozzi E, Tibaldi E, Cendron L, Zanotti G, Brunati AM, Vitadello M, Gorza L, Finotti P. Structural insights into complexes of glucose-regulated Protein94 (Grp94) with human immunoglobulin G. relevance for Grp94-lgG complexes that form in vivo in pathological conditions. PLoS One 2014;9:e86198.

128. Ferreira LR, Norris K, Smith T, Hebert C, Sauk JJ. Association of Hsp47, Grp78, and Grp94 with procollagen supports the successive or coupled action of molecular chaperones. J Cell Biochem 1994;56:518-526.

129. Ostrovsky O, Ahmed NT, Argon Y. The chaperone activity of GRP94 toward insulin-like growth factor II is necessary for the stress response to serum deprivation. Mol Biol Cell 2009;20:1855-1864.

130. Wanderling S, Simen BB, Ostrovsky O, Ahmed NT, Vogen SM, Gidalevitz T, Argon Y. GRP94 is essential for mesoderm induction and muscle development because it regulates insulin-like growth factor secretion. Mol Biol Cell 2007;18:3764-3775.

131. Ostrovsky O, Makarewich CA, Snapp EL, Argon Y. An essential role for ATP binding and hydrolysis in the chaperone activity of GRP94 in cells. Proc Natl Acad Sci USA 2009;106:11600-11605.

132. Anelli T, van Anken E. Missing links in antibody assembly control. Int J Cell Biol 2013;2013:606703.

133. Liu B, Yang Y, Qiu Z, Staron M, Hong F, Li Y, Wu S, Li Y, Hao B, Bona R, Han D, Li Z. Folding of Toll-like receptors by the HSP90 paralogue gp96 requires a substrate-specific cochaperone. Nat Commun 2010;1:79.

134. Flach H, Rosenbaum M, Duchniewicz M, Kim S, Zhang SL, Cahalan MD, Mittler G, Grosschedl R. Mzb1 protein regulates calcium homeostasis, antibody secretion, and integrin activation in innate-like B cells. Immunity 2010;33:723-735.

135. Rosenbaum M, Andreani V, Kapoor T, Herp S, Flach H, Duchniewicz M, Grosschedl R. MZB1 is a GRP94 cochaperone that enables proper immunoglobulin heavy chain biosynthesis upon ER stress. Genes Dev 2014;28:1165-1178.

136. van Anken E, Pena F, Hafkemeijer N, Christis C, Romijn EP, Grauschopf U, Oorschot VM, Pertel T, Engels S, Ora A, Lastun V, Glockshuber R, Klumperman J, Heck AJ, Luban J, et al. Efficient IgM assembly and secretion require the plasma cell induced endoplasmic reticulum protein $p E R p 1$. Proc Natl Acad Sci USA 2009;106:17019-17024.

137. Melnick J, Dul JL, Argon Y. Sequential interaction of the chaperones BiP and GRP94 with immunoglobulin chains in the endoplasmic reticulum. Nature 1994;370:373-375.

138. Eletto D, Dersh D, Argon Y. GRP94 in ER quality control and stress responses. Semin Cell Dev Biol 2010;21:479-485.

139. Argon Y, Simen BB. GRP94, an ER chaperone with protein and peptide binding properties. Semin Cell Dev Biol 1999;10:495-505.

140. Cheng HN, Bovey FA. Cis-trans equilibrium and kinetic studies of acetyl-L-proline and glycyl-L-proline. Biopolymers 1977;16:1465-1472.

141. Brandts JF, Halvorson HR, Brennan M. Consideration of the possibility that the slow step in protein denaturation reactions is due to cis-trans isomerism of proline residues. Biochemistry 1975;14:4953-4963.

142. Frech C, Schmid FX. DsbA-mediated disulfide bond formation and catalyzed prolyl isomerization in oxidative protein folding. J Biol Chem 1995;270:5367-5374.

143. Ishikawa Y, Vranka JA, Boudko SP, Pokidysheva E, Mizuno K, Zientek K, Keene DR, Rashmir-Raven AM, Nagata K, Winand NJ, Bachinger HP. Mutation in cyclophilin B that causes hyperelastosis cutis in American Quarter Horse does not affect peptidylprolyl cis-trans isomerase activity but shows altered cyclophilin B-protein interactions and affects collagen folding. J Biol Chem 2012;287:22253-22265.

144. Lang K, Schmid FX, Fischer G. Catalysis of protein folding by prolyl isomerase. Nature 1987;329:268-270.

145. Schmid FX, Baldwin RL. Acid catalysis of the formation of the slow-folding species of RNase $A$ : evidence that the reaction is proline isomerization. Proc Natl Acad Sci USA 1978;75:4764-4768.

146. Schmidpeter PA, Schmid FX. Prolyl isomerization and its catalysis in protein folding and protein function. J Mol Biol 2015;427:1609-1631.

147. Bachinger HP, Bruckner P, Timpl R, Prockop DJ, Engel J. Folding mechanism of the triple helix in type-III collagen and type-III pN-collagen. Role of disulfide bridges and peptide bond isomerization. Eur J Biochem 1980;106:619-632.

148. Morgan AA, Rubenstein E. Proline: the distribution, frequency, positioning, and common functional roles of proline and polyproline sequences in the human proteome. PLOS One 2013;8:e53785.

149. Juy M, Lam-Thanh $H$, Lintner $K$, Fermandjian S. Conformation and mobility of tyrosine side chain in tetrapeptides. Specific effects of 
cis- and trans-proline in Tyr-Pro- and Pro-Tyr-segments. Int J Pept Protein Res 1983;22:437-449.

150. Grathwohl C, Wuthrich K. Nmr studies of the molecular conformations in the linear oligopeptides $\mathrm{H}$-(L-Ala)n-L-Pro-OH. Biopolymers 1976;15:2043-2057.

151. Horibe T, Yosho C, Okada S, Tsukamoto M, Nagai H, Hagiwara Y, Tujimoto $Y$, Kikuchi M. The chaperone activity of protein disulfide isomerase is affected by cyclophilin B and cyclosporin A in vitro. J Biochem 2002;132:401-407.

152. Jansen $G$, Maattanen $P$, Denisov AY, Scarffe L, Schade B, Balghi $H$, Dejgaard K, Chen LY, Muller WJ, Gehring K, Thomas DY. An interaction map of endoplasmic reticulum chaperones and foldases. Mol Cell Proteomics 2012;11:710-723.

153. MacArthur MW, Thornton JM. Influence of proline residues on protein conformation. J Mol Biol 1991;218:397-412.

154. Stewart DE, Sarkar A, Wampler JE. Occurrence and role of cis peptide bonds in protein structures. J Mol Biol 1990;214:253-260.

155. Vitagliano L, Berisio R, Mastrangelo A, Mazzarella L, Zagari A. Preferred proline puckerings in cis and trans peptide groups: implications for collagen stability. Protein Sci 2001;10:2627-2632.

156. Safavi-Hemami H, Bulaj G, Olivera BM, Williamson NA, Purcell AW. Identification of Conus peptidylprolyl cis-trans isomerases (PPlases) and assessment of their role in the oxidative folding of conotoxins. J Biol Chem 2010;285:12735-12746.

157. Boulegue C, Milbradt AG, Renner C, Moroder L. Single proline residues can dictate the oxidative folding pathways of cysteine-rich peptides. J Mol Biol 2006;358:846-856.

158. Schwanhausser B, Busse D, Li N, Dittmar G, Schuchhardt J, Wolf J, Chen W, Selbach M. Global quantification of mammalian gene expression control. Nature 2011;473:337-342.

159. Scholz C, Rahfeld J, Fischer G, Schmid FX. Catalysis of protein folding by parvulin. J Mol Biol 1997;273:752-762.

160. Rahfeld J-U, Schierhorn A, Mann K, Fischer G. A novel peptidyl-prolyl cis/trans isomerase from Escherichia coli. FEBS Lett 1994;343:65-69.

161. Pastorino L, Sun A, Lu PJ, Zhou XZ, Balastik M, Finn G, Wulf G, Lim J, Li SH, Li X, Xia W, Nicholson LK, Lu KP. The prolyl isomerase Pin1 regulates amyloid precursor protein processing and amyloid-beta production. Nature 2006;440:528-534.

162. Fanghanel J, Fischer G. Insights into the catalytic mechanism of peptidyl prolyl cis/trans isomerases. Front Biosci 2004;9:3453-3478.

163. Liu J, Chen CM, Walsh CT. Human and Escherichia coli cyclophilins: sensitivity to inhibition by the immunosuppressant cyclosporin A correlates with a specific tryptophan residue. Biochemistry 1991;30:2306-2310.

164. Siekierka JJ, Hung SH, Poe M, Lin CS, Sigal NH. A cytosolic binding protein for the immunosuppressant FK506 has peptidyl-prolyl isomerase activity but is distinct from cyclophilin. Nature 1989;341:755-757.

165. Lee J, Choi TG, Ha J, Kim SS. Cyclosporine A suppresses immunoglobulin $\mathrm{G}$ biosynthesis via inhibition of cyclophilin $B$ in murine hybridomas and B cells. Int Immunopharmacol 2012;12:42-49.
166. Jessop CE, Tavender TJ, Watkins RH, Chambers JE, Bulleid NJ. Substrate specificity of the oxidoreductase ERp57 is determined primarily by its interaction with calnexin and calreticulin. J Biol Chem 2009;284:2194-2202.

167. Jessop CE, Watkins RH, Simmons JJ, Tasab M, Bulleid NJ. Protein disulphide isomerase family members show distinct substrate specificity: P5 is targeted to BiP client proteins. J Cell Sci 2009;122(Pt 23):4287-4295.

168. Eichmann C, Preissler S, Riek R, Deuerling E. Cotranslational structure acquisition of nascent polypeptides monitored by NMR spectroscopy. Proc Natl Acad Sci USA 2010;107:9111-9116.

169. Waudby CA, Launay H, Cabrita LD, Christodoulou J. Protein folding on the ribosome studied using NMR spectroscopy. Prog Nucl Magn Reson Spectrosc 2013;74:57-75.

170. Rajabi K, Reuther J, Deuerling E, Radford SE, Ashcroft AE. A comparison of the folding characteristics of free and ribosome-tethered polypeptide chains using limited proteolysis and mass spectrometry. Protein Sci 2015;24:1282-1291.

171. von der Malsburg K, Shao S, Hegde RS. The ribosome quality control pathway can access nascent polypeptides stalled at the Sec61 translocon. Mol Biol Cell 2015;26:2168-2180.

172. Solda T, Garbi N, Hammerling GJ, Molinari M. Consequences of ERp57 deletion on oxidative folding of obligate and facultative clients of the calnexin cycle. J Biol Chem 2006;281:6219-6226.

173. Wilson R, Allen AJ, Oliver J, Brookman JL, High S, Bulleid NJ. The translocation, folding, assembly and redox-dependent degradation of secretory and membrane proteins in semi-permeabilized mammalian cells. Biochem J 1995;307(Pt 3):679-687.

174. Sanyal S, Ashour J, Maruyama T, Altenburg AF, Cragnolini JJ, Bilate A, Avalos AM, Kundrat L, Garcia-Sastre A, Ploegh HL. Type I interferon imposes a TSG101/ISG15 checkpoint at the Golgi for glycoprotein trafficking during influenza virus infection. Cell Host Microbe 2013;14:510-521.

175. Bulleid NJ, Freedman RB. Defective co-translational formation of disulphide bonds in protein disulphide-isomerase-deficient microsomes. Nature 1988;335:649-651.

176. Matsumura Y, Rooney L, Skach WR. In vitro methods for CFTR biogenesis. Methods Mol Biol 2011;741:233-253.

177. Marquardt T, Hebert DN, Helenius A. Post-translational folding of influenza hemagglutinin in isolated endoplasmic reticulum-derived microsomes. J Biol Chem 1993;268:19618-19625.

178. Chen W, Helenius J, Braakman I, Helenius A. Cotranslational folding and calnexin binding during glycoprotein synthesis. Proc Natl Acad Sci USA 1995;92:6229-6233.

179. Kleizen B, van Vlijmen T, de Jonge HR, Braakman I. Folding of CFTR is predominantly cotranslational. Mol Cell 2005;20:277-287.

180. Hoelen H, Kleizen B, Schmidt A, Richardson J, Charitou P, Thomas PJ, Braakman I. The primary folding defect and rescue of DeltaF508 CFTR emerge during translation of the mutant domain. PLoS One 2010;5:e15458.

181. Lodish HF, Kong N, Snider M, Strous GJ. Hepatoma secretory proteins migrate from rough endoplasmic reticulum to Golgi at characteristic rates. Nature 1983;304:80-83. 
182. Hammond C, Helenius A. Folding of VSV G protein: sequential interaction with BiP and calnexin. Science 1994;266:456-458.

183. Kosuri P, Alegre-Cebollada J, Feng J, Kaplan A, Ingles-Prieto A, Badilla CL, Stockwell BR, Sanchez-Ruiz JM, Holmgren A, Fernandez $J M$. Protein folding drives disulfide formation. Cell 2012;151:794-806.

184. Qin M, Wang W, Thirumalai D. Protein folding guides disulfide bond formation. Proc Natl Acad Sci USA 2015;112:11241-11246.

185. Weiss MA. Diabetes mellitus due to the toxic misfolding of proinsulin variants. FEBS Lett 2013;587:1942-1950.

186. Braakman I, Helenius J, Helenius A. Manipulating disulfide bond formation and protein folding in the endoplasmic reticulum. EMBO J 1992;11:1717-1722.

187. Braakman I, Helenius J, Helenius A. Role of ATP and disulphide bonds during protein folding in the endoplasmic reticulum. Nature 1992;356:260-262.

188. Tatu U, Braakman I, Helenius A. Membrane glycoprotein folding, oligomerization and intracellular transport: effects of dithiothreitol in living cells. EMBO J 1993;12:2151-2157.

189. de Silva A, Braakman I, Helenius A. Posttranslational folding of vesicular stomatitis virus $G$ protein in the ER: involvement of noncovalent and covalent complexes. J Cell Biol 1993; 120:647-655.

190. Maggioni MC, Liscaljet IM, Braakman I. A critical step in the folding of influenza virus $\mathrm{HA}$ determined with a novel folding assay. Nat Struct Mol Biol 2005;12:258-263.

191. van Anken E, Sanders RW, Liscaljet IM, Land A, Bontjer I, Tillemans S, Nabatov AA, Paxton WA, Berkhout B, Braakman I. Only five of 10 strictly conserved disulfide bonds are essential for folding and eight for function of the HIV-1 envelope glycoprotein. Mol Biol Cell 2008;19:4298-4309.

192. Singh RR, Appu Rao AG. Reductive unfolding and oxidative refolding of a Bowman-Birk inhibitor from horsegram seeds (Dolichos biflorus): evidence for "hyperreactive" disulfide bonds and rate-limiting nature of disulfide isomerization in folding. Biochim Biophys Acta 2002;1597:280-291.

193. Ellgaard L. Catalysis of disulphide bond formation in the endoplasmic reticulum. Biochem Soc Trans 2004;32(Pt 5):663-667.

194. Haran G. How, when and why proteins collapse: the relation to folding. Curr Opin Struct Biol 2012;22:14-20.

195. Galligan JJ, Petersen DR. The human protein disulfide isomerase gene family. Hum Genomics 2012;6:6.

196. Okumura M, Kadokura H, Inaba K. Structures and functions of protein disulfide isomerase family members involved in proteostasis in the endoplasmic reticulum. Free Radic Biol Med 2015;83:314-322.

197. Kojer K, Riemer J. Balancing oxidative protein folding: the influences of reducing pathways on disulfide bond formation. Biochim Biophys Acta 2014;1844:1383-1390.

198. Schwaller M, Wilkinson B, Gilbert HF. Reduction-reoxidation cycles contribute to catalysis of disulfide isomerization by protein-disulfide isomerase. J Biol Chem 2003;278:7154-7159.
199. Molinari M, Helenius A. Glycoproteins form mixed disulphides with oxidoreductases during folding in living cells. Nature 1999;402:90-93.

200. Oliver JD, van der Wal FJ, Bulleid NJ, High S. Interaction of the thiol-dependent reductase ERp57 with nascent glycoproteins. Science 1997;275:86-88.

201. Rutkevich LA, Cohen-Doyle MF, Brockmeier U, Williams DB. Functional relationship between protein disulfide isomerase family members during the oxidative folding of human secretory proteins. Mol Biol Cell 2010;21:3093-3105.

202. Bulleid NJ, Ellgaard L. Multiple ways to make disulfides. Trends Biochem Sci 2011;36:485-492.

203. Konno T, Pinho Melo E, Lopes C, Mehmeti I, Lenzen S, Ron D, Avezov E. ERO1-independent production of $\mathrm{H} 2 \mathrm{O} 2$ within the endoplasmic reticulum fuels Prdx4-mediated oxidative protein folding. J Cell Biol 2015;211:253-259.

204. Araki K, lemura S, Kamiya Y, Ron D, Kato K, Natsume T, Nagata K. Ero1-alpha and PDIs constitute a hierarchical electron transfer network of endoplasmic reticulum oxidoreductases. J Cell Biol 2013;202:861-874.

205. Oka OB, Yeoh HY, Bulleid NJ. Thiol-disulfide exchange between the PDI family of oxidoreductases negates the requirement for an oxidase or reductase for each enzyme. Biochem J 2015;469:279-288.

206. Oka OB, Pringle MA, Schopp IM, Braakman I, Bulleid NJ. ERdj5 is the $E R$ reductase that catalyzes the removal of non-native disulfides and correct folding of the LDL receptor. Mol Cell 2013;50:793-804.

207. Appenzeller-Herzog C. Glutathione- and non-glutathione-based oxidant control in the endoplasmic reticulum. J Cell Sci 2011;124(Pt 6):847-855.

208. Bulleid NJ, van Lith M. Redox regulation in the endoplasmic reticulum. Biochem Soc Trans 2014;42:905-908.

209. Koritzinsky M, Levitin F, van den Beucken T, Rumantir RA, Harding NJ, Chu KC, Boutros PC, Braakman I, Wouters BG. Two phases of disulfide bond formation have differing requirements for oxygen. J Cell Biol 2013;203:615-627.

210. Shrimal S, Cherepanova NA, Gilmore R. Cotranslational and posttranslocational $\mathrm{N}$-glycosylation of proteins in the endoplasmic reticulum. Semin Cell Dev Biol 2015;41:71-78.

211. Helenius A. How N-linked oligosaccharides affect glycoprotein folding in the endoplasmic reticulum. Mol Biol Cell 1994;5:253-265.

212. Price JL, Culyba EK, Chen W, Murray AN, Hanson SR, Wong CH, Powers ET, Kelly JW. N-glycosylation of enhanced aromatic sequons to increase glycoprotein stability. Biopolymers 2012;98:195-211.

213. Zhang $Y$, Kozlov $G$, Pocanschi CL, Brockmeier U, Ireland BS, Maattanen P, Howe C, Elliott T, Gehring K, Williams DB. ERp57 does not require interactions with calnexin and calreticulin to promote assembly of class I histocompatibility molecules, and it enhances peptide loading independently of its redox activity. J Biol Chem 2009;284:10160-10173.

214. Schallus T, Feher K, Sternberg U, Rybin V, Muhle-Goll C. Analysis of the specific interactions between the lectin domain of malectin and diglucosides. Glycobiology 2010;20:1010-1020. 
215. Schallus T, Jaeckh C, Feher K, Palma AS, Liu Y, Simpson JC, Mackeen M, Stier G, Gibson TJ, Feizi T, Pieler T, Muhle-Goll C. Malectin: a novel carbohydrate-binding protein of the endoplasmic reticulum and a candidate player in the early steps of protein N-glycosylation. Mol Biol Cell 2008;19:3404-3414.

216. Galli C, Bernasconi R, Solda T, Calanca V, Molinari M. Malectin participates in a backup glycoprotein quality control pathway in the mammalian ER. PLoS One 2011;6:e16304.

217. Helenius A, Aebi M. Roles of N-linked glycans in the endoplasmic reticulum. Annu Rev Biochem 2004;73:1019-1049.

218. Denzel A, Molinari M, Trigueros C, Martin JE, Velmurgan S, Brown S, Stamp G, Owen MJ. Early postnatal death and motor disorders in mice congenitally deficient in calnexin expression. Mol Cell Biol 2002;22:7398-7404.

219. Mesaeli N, Nakamura K, Zvaritch E, Dickie P, Dziak E, Krause KH, Opas M, MacLennan DH, Michalak M. Calreticulin is essential for cardiac development. J Cell Biol 1999;144:857-868.

220. Okiyoneda T, Niibori A, Harada K, Kohno T, Michalak M, Duszyk M, Wada I, Ikawa M, Shuto T, Suico MA, Kai H. Role of calnexin in the ER quality control and productive folding of CFTR; differential effect of calnexin knockout on wild-type and DeltaF508 CFTR. Biochim Biophys Acta 2008;1783:1585-1594.

221. Molinari M, Helenius A. Chaperone selection during glycoprotein translocation into the endoplasmic reticulum. Science 2000;288:331-333.

222. Vanoni O, Paganetti P, Molinari M. Consequences of individual $\mathrm{N}$-glycan deletions and of proteasomal inhibition on secretion of active BACE. Mol Biol Cell 2008;19:4086-4098.

223. Tokhtaeva $E$, Sachs $G$, Vagin O. Diverse pathways for maturation of the Na,K-ATPase beta1 and beta2 subunits in the endoplasmic reticulum of Madin-Darby canine kidney cells. J Biol Chem 2010;285:39289-39302.

224. Negroiu G, Dwek RA, Petrescu SM. Folding and maturation of tyrosinase-related protein-1 are regulated by the post-translational formation of disulfide bonds and by N-glycan processing. J Biol Chem 2000;275:32200-32207.

225. Hulleman JD, Kelly JW. Genetic ablation of N-linked glycosylation reveals two key folding pathways for R345W fibulin-3, a secreted protein associated with retinal degeneration. FASEB J 2015;29:565-575.

226. Wang N, Glidden EJ, Murphy SR, Pearse BR, Hebert DN. The cotranslational maturation program for the type II membrane glycoprotein influenza neuraminidase. J Biol Chem 2008;283:33826-33837.

227. Vacca F, D'Ambrosi N, Nestola V, Amadio S, Giustizieri M, Cucchiaroni ML, Tozzi A, Velluz MC, Mercuri NB, Volonte C. $\mathrm{N}$-Glycans mutations rule oligomeric assembly and functional expression of P2X3 receptor for extracellular ATP. Glycobiology 2011;21:634-643.

228. Cioaca D, Ghenea S, Spiridon LN, Marin M, Petrescu AJ, Petrescu SM. C-terminus glycans with critical functional role in the maturation of secretory glycoproteins. PLoS One 2011;6:e19979.
229. Hang Q, Zhou Y, Hou S, Zhang D, Yang X, Chen J, Ben Z, Cheng C, Shen $A$. Asparagine-linked glycosylation of bone morphogenetic protein-2 is required for secretion and osteoblast differentiation. Glycobiology 2014;24:292-304.

230. Ishmael SS, Ishmael FT, Jones AD, Bond JS. Protease domain glycans affect oligomerization, disulfide bond formation, and stability of the meprin A metalloprotease homo-oligomer. J Biol Chem 2006;281:37404-37415.

231. McKinnon TA, Goode EC, Birdsey GM, Nowak AA, Chan AC, Lane DA, Laffan MA. Specific N-linked glycosylation sites modulate synthesis and secretion of von Willebrand factor. Blood 2010;116:640-648.

232. Hebert DN, Zhang JX, Chen W, Foellmer B, Helenius A. The number and location of glycans on influenza hemagglutinin determine folding and association with calnexin and calreticulin. J Cell Biol 1997;139:613-623.

233. Carvalho S, Catarino TA, Dias AM, Kato M, Almeida A, Hessling B, Figueiredo J, Gartner F, Sanches JM, Ruppert T, Miyoshi E, Pierce M, Carneiro F, Kolarich D, Seruca R, et al. Preventing E-cadherin aberrant N-glycosylation at Asn-554 improves its critical function in gastric cancer. Oncogene 2015. doi: 10.1038/onc.2015.225.

234. Tate MD, Brooks AG, Reading PC. Specific sites of $\mathrm{N}$-linked glycosylation on the hemagglutinin of $\mathrm{H} 1 \mathrm{~N} 1$ subtype influenza $A$ virus determine sensitivity to inhibitors of the innate immune system and virulence in mice. J Immunol 2011;187:1884-1894.

235. Zhu Q, Kao L, Azimov R, Abuladze N, Newman D, Kurtz I. Interplay between disulfide bonding and $\mathrm{N}$-glycosylation defines SLC4 $\mathrm{Na}+$-coupled transporter extracellular topography. J Biol Chem 2015;290:5391-5404.

236. Jessop CE, Chakravarthi S, Garbi N, Hammerling GJ, Lovell S, Bulleid NJ. ERp57 is essential for efficient folding of glycoproteins sharing common structural domains. EMBO J 2007;26:28-40.

237. Aebi M. N-linked protein glycosylation in the ER. Biochim Biophys Acta 2013;1833:2430-2437.

238. Lizak C, Gerber S, Numao S, Aebi M, Locher KP. X-ray structure of a bacterial oligosaccharyltransferase. Nature 2011;474:350-355.

239. Holst B, Bruun AW, Kielland-Brandt MC, Winther JR. Competition between folding and glycosylation in the endoplasmic reticulum. EMBO J 1996;15:3538-3546.

240. Bulleid NJ, Bassel-Duby RS, Freedman RB, Sambrook JF, Gething MJ. Cell-free synthesis of enzymically active tissue-type plasminogen activator. Protein folding determines the extent of $\mathrm{N}$-linked glycosylation. Biochem J 1992;286(Pt 1):275-280.

241. Allen S, Naim HY, Bulleid NJ. Intracellular folding of tissue-type plasminogen activator. Effects of disulfide bond formation on $\mathrm{N}$-linked glycosylation and secretion. J Biol Chem 1995;270:4797-4804.

242. Ermonval M, Duvet S, Zonneveld D, Cacan R, Buttin G, Braakman I. Truncated N-glycans affect protein folding in the ER of $\mathrm{CHO}$-derived mutant cell lines without preventing calnexin binding. Glycobiology 2000; 10:77-87.

243. Schulz BL, Stirnimann CU, Grimshaw JP, Brozzo MS, Fritsch F, Mohorko E, Capitani G, Glockshuber R, Grutter MG, Aebi M. 
Oxidoreductase activity of oligosaccharyltransferase subunits Ost3p and Ost6p defines site-specific glycosylation efficiency. Proc Natl Acad Sci USA 2009;106:11061-11066.

244. Cherepanova NA, Shrimal S, Gilmore R. Oxidoreductase activity is necessary for $\mathrm{N}$-glycosylation of cysteine-proximal acceptor sites in glycoproteins. J Cell Biol 2014;206:525-539.

245. Wilcox C, Hu JS, Olson EN. Acylation of proteins with myristic acid occurs cotranslationally. Science 1987;238:1275-1278.

246. Deichaite I, Casson LP, Ling HP, Resh MD. In vitro synthesis of pp60v-src: myristylation in a cell-free system. Mol Cell Biol 1988:8:4295-4301.

247. Gripon P, Le Seyec J, Rumin S, Guguen-Guillouzo C. Myristylation of the hepatitis $B$ virus large surface protein is essential for viral infectivity. Virology 1995;213:292-299.

248. Persing DH, Varmus HE, Ganem D. The preS1 protein of hepatitis $B$ virus is acylated at its amino terminus with myristic acid. J Virol 1987;61:1672-1677.

249. Charollais J, Van Der Goot FG. Palmitoylation of membrane proteins (Review). Mol Membr Biol 2009;26:55-66.

250. Maeda A, Okano K, Park PS, Lem J, Crouch RK, Maeda T, Palczewski K. Palmitoylation stabilizes unliganded rod opsin. Proc Natl Acad Sci USA 2010;107:8428-8433.

251. Meckler X, Roseman J, Das P, Cheng H, Pei S, Keat M, Kassarjian B, Golde TE, Parent AT, Thinakaran G. Reduced Alzheimer's disease ss-amyloid deposition in transgenic mice expressing S-palmitoylation-deficient APH1aL and nicastrin. J Neurosci 2010;30:16160-16169.

252. Motoki K, Kume H, Oda A, Tamaoka A, Hosaka A, Kametani F, Araki $W$. Neuronal beta-amyloid generation is independent of lipid raft association of beta-secretase BACE1: analysis with a palmitoylation-deficient mutant. Brain Behav 2012;2:270-282.

253. Lynes EM, Bui M, Yap MC, Benson MD, Schneider B, Ellgaard L, Berthiaume LG, Simmen T. Palmitoylated TMX and calnexin target to the mitochondria-associated membrane. EMBO J 2012;31: 457-470.

254. Lynes EM, Raturi A, Shenkman M, Ortiz Sandoval C, Yap MC, Wu J, Janowicz A, Myhill N, Benson MD, Campbell RE, Berthiaume LG, Lederkremer GZ, Simmen T. Palmitoylation is the switch that assigns calnexin to quality control or ER $\mathrm{Ca}^{2+}$ signaling. J Cell Sci 2013;126(Pt 17):3893-3903.

255. McClure ML, Wen H, Fortenberry J, Hong JS, Sorscher EJ. S-palmitoylation regulates biogenesis of core glycosylated wild-type and F508del CFTR in a post-ER compartment. Biochem J 2014;459:417-425.

256. Engel $S$, de Vries M, Herrmann A, Veit M. Mutation of a raft-targeting signal in the transmembrane region retards transport of influenza virus hemagglutinin through the Golgi. FEBS Lett 2012;586:277-282.

257. Abrami L, Kunz B, lacovache I, van der Goot FG. Palmitoylation and ubiquitination regulate exit of the Wnt signaling protein LRP6 from the endoplasmic reticulum. Proc Natl Acad Sci USA 2008;105: 5384-5389.
258. Blaskovic S, Blanc M, van der Goot FG. What does S-palmitoylation do to membrane proteins? FEBS J 2013;280:2766-2774.

259. Fredericks GJ, Hoffmann FW, Rose AH, Osterheld HJ, Hess FM, Mercier $F$, Hoffmann PR. Stable expression and function of the inositol 1,4,5-triphosphate receptor requires palmitoylation by a DHHC6/selenoprotein K complex. Proc Natl Acad Sci USA 2014;111:16478-16483.

260. Lakkaraju AK, Abrami L, Lemmin T, Blaskovic S, Kunz B, Kihara A, Dal Peraro M, van der Goot FG. Palmitoylated calnexin is a key component of the ribosome-translocon complex. EMBO J 2012;31: $1823-1835$.

261. Ishikawa Y, Boudko S, Bachinger HP. Ziploc-ing the structure: triple helix formation is coordinated by rough endoplasmic reticulum resident PPlases. Biochim Biophys Acta 2015;1850:1983-1993.

262. Berg RA, Prockop DJ. The thermal transition of a non-hydroxylated form of collagen. Evidence for a role for hydroxyproline in stabilizing the triple-helix of collagen. Biochem Biophys Res Commun 1973;52: $115-120$.

263. Bachinger HP, Bruckner P, Timpl R, Engel J. The role of cis-trans isomerization of peptide bonds in the coil leads to and comes from triple helix conversion of collagen. Eur J Biochem 1978;90:605-613.

264. Bruckner P, Eikenberry EF. Formation of the triple helix of type I procollagen in cellulo. Temperature-dependent kinetics support a model based on cis in equilibrium trans isomerization of peptide bonds. Eur J Biochem 1984;140:391-395.

265. Morello R, Bertin TK, Chen Y, Hicks J, Tonachini L, Monticone M, Castagnola P, Rauch F, Glorieux FH, Vranka J, Bachinger HP, Pace $J M$, Schwarze $U$, Byers PH, Weis M, et al. CRTAP is required for prolyl 3-hydroxylation and mutations cause recessive osteogenesis imperfecta. Cell 2006;127:291-304.

266. Ishida Y, Nagata K. Hsp47 as a collagen-specific molecular chaperone. Methods Enzymol 2011;499:167-182.

267. Szarka A, Lorincz T. The role of ascorbate in protein folding. Protoplasma 2014;251:489-497.

268. Zito E, Hansen HG, Yeo GS, Fujii J, Ron D. Endoplasmic reticulum thiol oxidase deficiency leads to ascorbic acid depletion and noncanonical scurvy in mice. Mol Cell 2012;48:39-51.

269. Wang Y, Lam KS, Yau MH, Xu A. Post-translational modifications of adiponectin: mechanisms and functional implications. Biochem J 2008;409:623-633.

270. Lopez-Vera E, Walewska A, Skalicky JJ, Olivera BM, Bulaj G. Role of hydroxyprolines in the in vitro oxidative folding and biological activity of conotoxins. Biochemistry 2008;47:1741-1751.

271. Pokidysheva E, Zientek KD, Ishikawa Y, Mizuno K, Vranka JA, Montgomery NT, Keene DR, Kawaguchi T, Okuyama K, Bachinger HP. Posttranslational modifications in type I collagen from different tissues extracted from wild type and prolyl 3-hydroxylase 1 null mice. J Biol Chem 2013;288:24742-24752.

272. Hebert DN, Lamriben L, Powers ET, Kelly JW. The intrinsic and extrinsic effects of $\mathrm{N}$-linked glycans on glycoproteostasis. Nat Chem Biol 2014;10:902-910. 
Ellgaard et al.

273. Costantini C, Ko MH, Jonas MC, Puglielli L. A reversible form of lysine acetylation in the ER and Golgi lumen controls the molecular stabilization of BACE1. Biochem J 2007;407:383-395.

274. Pehar M, Lehnus M, Karst A, Puglielli L. Proteomic assessment shows that many endoplasmic reticulum (ER)-resident proteins are targeted by $\mathrm{N}$ (epsilon)-lysine acetylation in the lumen of the organelle and predicts broad biological impact. J Biol Chem 2012;287:22436-22440.

275. Ko MH, Puglielli L. Two endoplasmic reticulum (ER)/ER Golgi intermediate compartment-based lysine acetyltransferases post-translationally regulate BACE1 levels. J Biol Chem 2009;284:2482-2492.
276. Jonas MC, Costantini C, Puglielli L. PCSK9 is required for the disposal of non-acetylated intermediates of the nascent membrane protein BACE1. EMBO Rep 2008;9:916-922.

277. Pehar M, Puglielli L. Lysine acetylation in the lumen of the ER: a novel and essential function under the control of the UPR. Biochim Biophys Acta 2013;1833:686-697.

278. Peng Y, Li M, Clarkson BD, Pehar M, Lao PJ, Hillmer AT, Barnhart TE, Christian BT, Mitchell HA, Bendlin BB, Sandor M, Puglielli L. Deficient import of acetyl-COA into the ER lumen causes neurodegeneration and propensity to infections, inflammation, and cancer. J Neurosci 2014;34:6772-6789. 